\title{
Macrophage Matrix Metalloproteinase-9 Mediates Epithelial-Mesenchymal Transition in Vitro in Murine Renal Tubular Cells
}

Thian Kui Tan, Guoping Zheng, Tzu-Ting Hsu, Ying Wang, Vincent W.S. Lee, Xinrui Tian, Yiping Wang, Qi Cao, Ya Wang, and David C.H. Harris

From the Centre for Transplantation and Renal Research, the University of Sydney at Westmead Millennium Institute, Sydney, Australia

As a rich source of pro-fibrogenic growth factors and matrix metalloproteinases (MMPs), macrophages are well-placed to play an important role in renal fibrosis. However, the exact underlying mechanisms and the extent of macrophage involvement are unclear. Tubular cell epithelial-mesenchymal transition (EMT) is an important contributor to renal fibrosis and MMPs to induction of tubular cell EMT. The aim of this study was to investigate the contribution of macrophages and MMPs to induction of tubular cell EMT. The murine C1.1 tubular epithelial cell line and primary tubular epithelial cells were cultured in activated macrophage-conditioned medium (AMCM) derived from lipopolysaccharide-activated $\mathrm{J} 774$ macrophages. MMP-9, but not MMP-2 activity was detected in AMCM. AMCM-induced tubular cell EMT in C1.1 cells was inhibited by broad-spectrum MMP inhibitor (GM6001), MMP-2/9 inhibitor, and in AMCM after MMP-9 removal by monoclonal Ab against MMP-9. AMCMinduced EMT in primary tubular epithelial cells was inhibited by MMP-2/9 inhibitor. MMP-9 induced tubular cell EMT in both C1.1 cells and primary tubular epithelial cells. Furthermore, MMP-9 induced tubular cell EMT in C1.1 cells to an extent similar to transforming growth factor- $\beta$. Transforming growth factor- $\beta$-induced tubular cell EMT in C1.1 cells was inhibited by MMP-2/9 inhibitor. Our in vitro study provides evidence that MMPs, specifically MMP-9, secreted by effector macrophages can induce tubular cell EMT and thereby contribute to renal fibrosis. (AmJ Pathol 2010, 176:1256-1270; DOI: 10.2353/ajpath.2010.090188)
Interstitial macrophage infiltration is a hallmark of all progressive renal diseases regardless of the initial cause of the injury. ${ }^{1,2}$ Macrophages have long been known to play an important role in renal fibrosis, ${ }^{3}$ which is a central component of the final common pathway leading to renal failure. Previous studies have demonstrated a close association between macrophage infiltrate and excessive extracellular matrix protein accumulation in diseased human kidney as well as in experimental models. ${ }^{4-6}$ In addition, the number of infiltrating macrophages has been shown to correlate well with the number of myofibroblasts, ${ }^{7,8}$ the effector cells responsible for secretion of extracellular matrix proteins. A recent study revealed that blockade of macrophage recruitment in obstructive renal injury resulted in a reduction in renal fibrosis via tubular cell epithelial-mesenchymal transition (EMT), ${ }^{9}$ which has been recognized as an important source of myofibroblasts in renal fibrosis. However, the exact mechanism underlying the contribution of macrophages to renal fibrosis via tubular cell EMT remains undefined. As a major source of pro-fibrogenic growth factors and matrix metalloproteinases (MMPs), macrophages may be major determinants of the outcome of renal fibrosis.

Tubular cell EMT is a process by which tubular epithelial cells lose their epithelial characteristics and acquire a mesenchymal phenotype. This process has been recognized as one of several pathways contributing to the myofibroblast population in renal fibrosis. ${ }^{10}$ Despite emerging and conflicting evidence about the relative importance of various sources of myofibroblasts, ${ }^{11,12}$ it is generally accepted that tubular cell EMT plays an important role in renal fibrosis. Since the concept of tubular cell EMT was first proposed, numerous studies have pro-

Supported by Australian National Health and Medical Research Council (NHMRC) Project grant 402435, NHMRC Peter Doherty Fellowship, and Kidney Health Australia Biomedical Scholarship.

Accepted for publication November 6, 2009.

Supplemental material for this article can be found on http://ajp. amjpathol.org

Address reprint requests to Thian Kui Tan, BMedSc., Centre for Transplantation and Renal Research, the University of Sydney at Westmead Millennium Institute, Sydney, NSW 2145 Australia. E-mail: ttan4526@mail.usyd.edu.au. 
vided evidence for tubular cell EMT in various experimental models as well as in human biopsies. ${ }^{10}$ Furthermore, the importance of tubular cell EMT has been demonstrated by Iwano et $\mathrm{al}^{13}$ using transgenic mice and direct genetic tagging of tubular epithelial cells to show that more than a third of myofibroblasts in kidneys with unilateral ureteral obstruction are derived from tubular epithelial cells via tubular cell EMT. Moreover, blockade of tubular EMT has been shown to attenuate renal fibrosis in obstructive nephropathy. ${ }^{14}$ However, some controversy remains as to whether tubular cell EMT plays a consistent role in other experimental models, and its exact contribution in renal fibrosis is yet to be established.

Although pro-fibrogenic growth factors are well known as inducers of tubular cell EMT, cumulative evidence suggests an important role for MMPs. Traditionally, MMPs were thought to be antifibrogenic due to their ability to degrade extracellular matrix proteins, yet MMPs - in particular MMP-2 and MMP-9 - have been recognized as promoters of tubular cell EMT via basement membrane disruption. In fact, induction of tubular cell EMT in vitro ${ }^{15}$ and in vivo ${ }^{14}$ has been shown to be associated with increased expression of MMP-2 and MMP-9. Earlier studies have demonstrated that tubular epithelial cells undergoing mesenchymal transition are closely associated with damaged tubular basement membrane and that complete transition requires tubular basement membrane damage. ${ }^{16}$ Later studies have shown directly that MMPs can disrupt basement membrane integrity; loss of MMP-9 expression lead to preservation of basement membrane integrity and inhibition of tubular cell EMT in obstructed kidney of tissue type plasminogen activator knockout mice. ${ }^{14}$ Despite this evidence supporting induction of tubular cell EMT by MMPs, the precise contribution of MMPs may have been underestimated. In cancer research, MMPs are well known to directly induce EMT in tumor cells of epithelial origin and to promote tumor progression via basement membrane disruption. ${ }^{17}$ MMP-2 has been shown consistently to be necessary and sufficient to induce tubular cell EMT in a rat tubular epithelial cell line (NRK52e). ${ }^{18}$ In addition, recent studies from our laboratory have demonstrated that MMP-3 and MMP-9 are also capable of inducing tubular cell EMT in NRK52e cells via the disruption of the cell adhesion molecule E-cadherin. Finally, the fact that transforming growth factor (TGF)- $\beta$-induced tubular cell EMT in NRK52e was inhibited by a broad spectrum MMP inhibitor suggests a primary role of MMP in TGF- $\beta$-induced tubular cell EMT. ${ }^{19}$ Together, these data suggest that MMPs from macrophages may play a major role in induction of tubular cell EMT. Therefore the aim of this study was to investigate the contribution of macrophages and their secreted MMPs to the induction of tubular cell EMT.

\section{Materials and Methods}

\section{Cell Culture and Treatment}

Murine C1.1 tubular epithelial cell line (C1.1) was cultured in K1 medium (Dulbecco's Modified Eagle Medium
(DMEM):HAM's F12; 1:1 v/v) (Invitrogen, Carlsbad, CA) containing $25 \mu \mathrm{g} / \mathrm{ml}$ of epidermal growth factor (Sigma, St. Louis, MO), $25 \mu \mathrm{mol} / \mathrm{L}$ of HEPES (Invitrogen), hormone mixture, and $5 \%$ fetal calf serum (Invitrogen) at $37^{\circ} \mathrm{C}$ with $5 \% \mathrm{CO}_{2}$. For treatment, $\mathrm{C} 1.1$ cells were cultured under low density for 24 hours in complete medium, washed in PBS (Invitrogen) and replaced with activated macrophage conditioned medium (AMCM) alone; AMCM with broad spectrum MMP inhibitor GM6001 (25 $\mu \mathrm{mol} / \mathrm{L}$ ) (Calbiochem, Darmstatdt, Germany); AMCM with MMP2/9 inhibitor (1, 2, 3, and $4 \mu \mathrm{mol} / \mathrm{L})$ (Chemicon, Billerica, MA); AMCM with TGF- $\beta$ neutralizing antibody (Ab; 1D11) (at maximal inhibitory dosage of $30 \mu \mathrm{g} / \mathrm{ml}$ ) (R\&D Systems, Minneapolis, MN) or MMP-9 immunoprecipitated AMCM; serum free K1 medium with recombinant MMP-9 (rMMP-9) $(2 \mu \mathrm{g} / \mathrm{ml})$ (BIOMOL International, Plymouth Meeting, PA) alone or rMMP-9 with MMP-2/9 inhibitor ( $4 \mu \mathrm{mol} / \mathrm{L})$. For TGF- $\beta$ treatment, $\mathrm{C} 1.1$ cells were cultured under low density for 24 hours in complete medium, washed, and cultured in serum-free $\mathrm{K} 1$ medium with TGF- $\beta$ ( $3 \mathrm{ng} / \mathrm{ml}$ ) (Biosource, Camarillo, CA) alone, TGF- $\beta$ with GM6001 (25 $\mu \mathrm{mol} / \mathrm{L})$, or TGF- $\beta$ with MMP-2/9 inhibitor (2, 3, and $5 \mu \mathrm{mol} / \mathrm{L})$.

Primary tubular epithelial cells (TECs) were obtained from the cortex of mouse (BALB/c) kidney using established methods adapted from Doctor et al. ${ }^{20}$ Freshly isolated primary proximal TECs were cultured in complete $\mathrm{K} 1$ medium with $5 \%$ fetal calf serum for 24 hours, washed and cultured in serum-free complete $\mathrm{K} 1$ medium for 4 to 5 days before treatment with AMCM alone or AMCM with MMP-2/9 inhibitor $(4 \mu \mathrm{mol} / \mathrm{L})$ or rMMP-9. Purity of primary TECs $(\geq 90 \%)$ was determined by indirect immunofluorescence staining for epithelial and mesenchymal markers.

\section{AMCM}

Murine macrophage cell line (J774) was cultured in DMEM (Invitrogen) supplemented with 10\% fetal calf serum. For activation, J774 cells were cultured in complete medium containing $10 \%$ fetal calf serum and $5 \mu \mathrm{g} / \mathrm{ml}$ of lipopolysaccharide (Sigma) for 24 hours, washed three times, and cultured in serum-free DMEM for 48 hours. After 48 hours, the medium was collected and filtered through a $0.22-\mu \mathrm{m}$ filter. DMEM from the final wash was collected, filtered, and used as the control medium for C1.1 cells under AMCM treatment. This served as a control for residual lipopolysaccharide in the AMCM.

\section{Morphological and Immunofluorescence Analysis}

For indirect immunofluorescence, cells cultured on glass coverslips or 8-well permanox chamber slides (Sigma) were washed twice with PBS, fixed with absolute methanol at $-20^{\circ} \mathrm{C}$ for 10 minutes, and blocked with $2 \%$ bovine serum albumin (Sigma) in PBS for 20 minutes at room temperature. Cells were then incubated with primary antibodies against epithelial markers [mouse monoclonal anti-E-cadherin (1:100; BD bioscience, San Jose, CA), rabbit polyclonal anti-cytokeratin (1:200; Abcam, Cambridge, UK), and mouse monoclonal anti- $\beta$-catenin (1: 
100; BD bioscience)] and mesenchymal markers [rabbit polyclonal anti- $\alpha$-smooth muscle actin (SMA, 1:300; Abcam), rabbit polyclonal anti-vimentin (1:200; Abcam), goat polyclonal anti-fibronectin (1:100; Santa Cruz Biotechnology, Santa Cruz, CA) and rabbit polyclonal anti$\mathrm{N}$-cadherin $(1 \mu \mathrm{g} / \mathrm{ml}$; Calbiochem)] in $2 \%$ bovine serum albumin in PBS for 1 hour at room temperature. Secondary goat anti-mouse lgG2a/2b fluorescein isothiocyanateconjugated antibodies (1:200; BD Biosciences Pharmingen) was used for E-cadherin, biotin-conjugated rabbit anti-mouse IgG1 for $\beta$-catenin (1:200; Zymed laboratories, South San Francisco, CA), goat-anti-rabbit Texas red conjugated antibodies (1:100; Calbiochem) for $\alpha$-SMA, biotin-conjugated goat anti-rabbit antibodies (1: 400; Zymed laboratories) for cytokeratin, vimentin, and $\mathrm{N}$-cadherin, and Alexa Fluor-488 (1:800; Invitrogen) for fibronectin. This was followed by the application of fluorescent conjugated strepavidin (1:200; eBioscience, San Diego, CA) for biotin-conjugated secondary antibodies. Cells were then washed twice with PBS, counterstained with 4',6-diamidino-2 phenylindole (Invitrogen) for 5 minutes, and washed twice again with PBS before mounting with fluorescence mounting medium (Dako, Glostrup, Denmark). For isotype Ab controls, mouse IgG2a, $\kappa$ (Biolegend, San Diego, CA) was used for E-cadherin, mouse IgG1 (Exbio Antibodies, Prague, Czech Republic) for $\beta$-catenin, rabbit IgG (Invitrogen) for cytokeratin, vimentin and $\mathrm{N}$-cadherin, goat IgG (Invitrogen) for fibronectin and their corresponding secondary antibodies were applied. Isotype control staining was performed on cells that were positive for epithelial or mesenchymal markers. Representative isotype control staining is shown for $\mathrm{C} 1.1$ cells and primary TECs when immunofluorescence staining was first performed for each marker.

For tissue staining, frozen kidney sections were cut at $5 \mu \mathrm{m}$, fixed with cold acetone at $-20^{\circ} \mathrm{C}$ for 10 minutes and blocked with $2 \%$ bovine serum albumin (Sigma) for 1 hour at room temperature. For macrophage (F4/80) with MMP-9 and $\alpha$-SMA with MMP-9 double immunofluorescence staining, tissue sections were sequentially stained with first primary $\mathrm{Ab}$ of rabbit polyclonal anti-MMP-9 (1: 200; Abcam) for 1 hour, first secondary Ab of goat antirabbit Texas red conjugated antibodies (1:100; Calbiochem) for 40 minutes, second primary Ab of monoclonal rat anti-mouse F4/80 (1:200: Abcam) or monoclonal antimouse $\alpha$-SMA (1:200: Sigma), and followed by second secondary of goat anti-rat fluorescein isothiocyanateconjugated antibodies (1:100; Biolegend, San Diego, $\mathrm{CA}$ ) or goat anti-mouse $\operatorname{lgG} 2 \mathrm{a} / 2 \mathrm{~b}$ fluorescein isothiocyanate-conjugated antibodies (1:200; BD Biosciences Pharmingen) for 40 minutes at room temperature, respectively. Tissue sections were washed three times with PBS between each staining and counterstained with $4^{\prime}, 6$-diamidino-2 phenylindole for 5 minutes before mounting with fluorescence mounting medium. Tissue sections were stained with Gomori trichrome for fibrosis.

\section{Real-Time Reverse Transcription-PCR Analysis}

RNA was extracted and purified from cells using RNeasy Mini Kit (Qiagen, Hilden, Germany) and RNA samples were quantified from UV absorbance at $260 \mathrm{~nm}$. cDNA was synthesized using $200 \mathrm{ng}$ of RNA in $20 \mu \mathrm{l}$ reaction buffer by reverse transcription using the Superscript First strand synthesis system (Invitrogen) and random hexamer primers at $50^{\circ} \mathrm{C}$ for 50 minutes. Designed primers and established primers from published papers were used for real-time reverse transcription (RT)-PCR (Table 1). Housekeeping gene $\beta$-actin was used as the internal control. For RT-PCR, $2 \mu \mathrm{l}$ of CDNA were used in a $25 \mu \mathrm{l}$ PCR mixture containing $10 \rho \mathrm{mol} / \mu \mathrm{l}$ of each primer, $5 \mathrm{U} / \mu \mathrm{l}$ of Red Hot Taq polymerase (Abgene, Rockford, IL) and the PCR consisted of 32 cycles at $94^{\circ} \mathrm{C}$ for 1 minute, 56 to $62^{\circ} \mathrm{C}$ for 30 seconds and $72^{\circ} \mathrm{C}$ for 1 minute. For negative control, cDNA was replaced with water. PCR products were size fractionated on $2 \%$ agarose gel (Promega, Madison, WI) in $1 \times$ Tris-Acetate-EDTA buffer (AMRESCO, Solon, OH) and detected by SYBR Green (AMRESCO) staining. For real-time PCR, PCR mixture contained $0.5 \mu \mathrm{l}$ of cDNA, $10 \rho \mathrm{mol} / \mu \mathrm{l}$ of each primer in a $20 \mu \mathrm{l}$ final volume of SYBR mastermix (Invitrogen). Amplification was performed using the Rotogene-6000 Real-Time Thermo cycler and was cycled for 2 minutes at $50^{\circ} \mathrm{C}, 10$ minutes at $95^{\circ} \mathrm{C}$, followed by 40 cycles at $95^{\circ} \mathrm{C}$ for 15 seconds and 1 minute at $60^{\circ} \mathrm{C}$.

\section{Semiquantitative Assessment of Cell Morphology}

Phase contrast images of control C1.1 and C1.1 cells under treatment on 12-well tissue culture plates were taken from a minimum of 10 consecutive fields of view with a total cell count of at least 2000 cells. Results were obtained from a duplicate for the control C1.1 and C1.1 cells under treatment per experiment and from a minimum of three independent experiments. Quantitation was performed by two observers blinded to the experimental treatments. Both observers were blinded to each other's results and the results obtained from both observers were almost identical. Determination of morphological changes was based on the classification of tubular epithelial cells as typical "cobblestone" in shape and appearing in clusters of variable size; and classification of fibroblasts as stellate, fusiform, or spindle in shape, and appearing as singular, scattered, or protruding/extending from the edge of a normal cluster of tubular epithelial cells.

\section{RNA Interference}

Gene silencing by small interfering RNA was used to silence the expression of MMP-9 in C1.1 cells. The small interfering (si)RNA sequence targeting murine MMP-9 (sc-29401) and negative control (sc-37007) were purchased from Santa Cruz Biotechnology. For siRNA reverse transfection, $2 \times 10^{5} \mathrm{C} 1.1$ cells were transfected with 60 pmol of MMP-9 or control siRNA using Lipofectamine 2000 (Invitrogen) in antibiotic-free and serum-free K1 medium. Following 6 hours of incubation, transfected cells were rinsed with PBS and treated with serum-free K1 medium with TGF- $\beta$ ( $3 \mathrm{ng} / \mathrm{ml})$ or with AMCM for 48 hours. 
Table 1. Primers Used for RT and Real-Time PCR

\begin{tabular}{|c|c|c|}
\hline Transcript & Sequence & Product (bp) \\
\hline iNOS & $\begin{array}{l}\text { Forward 5'-CACCTTGGAGTTCACCCAGT-3' } \\
\text { Reverse 5'-ACCACTCGTACTTGGGATGC-3' }\end{array}$ & 170 \\
\hline CCL-2 & $\begin{array}{l}\text { Forward 5'-CCCAATGAGTAGGCTGGAGA-3' } \\
\text { Reverse 5'-TCTGGACCCATTCCTTCTTG-3' }\end{array}$ & 125 \\
\hline TNF- $\alpha$ & $\begin{array}{l}\text { Forward 5'-GCTGAGCTCAAACCCTGGTA-3' } \\
\text { Reverse 5'-CGGACTCCGCAAAGTCTAAG-3' }\end{array}$ & 118 \\
\hline TGF- $\beta$ & $\begin{array}{l}\text { Forward 5'-AGACGGAATACAGGGCTTTCGATTCA-3' } \\
\text { Reverse 5'-CTTGGGCTTGCGACCCACGTAGTA-3' }\end{array}$ & 492 \\
\hline FGF & $\begin{array}{l}\text { Forward 5'-AGCGGCTCTACTGCAAGAAC-3' } \\
\text { Reverse 5'-TCGTTTCAGTGCCACATACC-3' }\end{array}$ & 298 \\
\hline EGF & $\begin{array}{l}\text { Forward 5'-TGTGTTATTGGCTATTCTGG-3' } \\
\text { Reverse 5'-TCTTGGGGTCTTGGTGTTTCT-3' }\end{array}$ & 322 \\
\hline IL-1 & $\begin{array}{l}\text { Forward 5'-TGCCATTGACCATCTCTCTCTG-3' } \\
\text { Reverse 5'-TGGCAACTCCTTCAGCAACACG-3' }\end{array}$ & 543 \\
\hline MMP-2 & $\begin{array}{l}\text { Forward 5'-AAGATTGACGCTGTGTAGAGG-3' } \\
\text { Reverse 5'-CACGACAGCATCCAGGTTATCAGG-3' }\end{array}$ & 308 \\
\hline MMP-3 & $\begin{array}{l}\text { Forward 5'-GTCCTCCACAGACTTGTCC-3' } \\
\text { Reverse 5'-TGCACATTGGTGATGTCTCAGG-3' }\end{array}$ & 154 \\
\hline MMP-7 & $\begin{array}{l}\text { Forward 5'-GATTTGATCCACTACGATC-3' } \\
\text { Reverse 5'-GTGGACAACCTCAAGGAAATGC-3' }\end{array}$ & 224 \\
\hline MMP-9 & $\begin{array}{l}\text { Forward 5'-CAAAACTACTCTGAAGACTTGC-3' } \\
\text { Reverse 5'-AATGGGCATCTCCCTGAACG-3' }\end{array}$ & 240 \\
\hline E-cadherin & $\begin{array}{l}\text { Forward 5'-AGAGGAGAGTCGAAGTGCCCG-3' } \\
\text { Reverse 5'-GCAATGGGTGAACCATCATCTG-3' }\end{array}$ & 260 \\
\hline Cytokeratin & $\begin{array}{l}\text { Forward 5'-GTCAGAGCTGGCACAAACTCG-3' } \\
\text { Reverse 5'-CTCTGCCATCCACGATCTTACG-3' }\end{array}$ & 221 \\
\hline$\alpha$-SMA & $\begin{array}{l}\text { Forward 5'-TTCCTTCGTGACTACTGCCG-3' } \\
\text { Reverse 5'-GCTGACTCCATCCCAATGAAAG-3' }\end{array}$ & 226 \\
\hline Vimentin & $\begin{array}{l}\text { Forward 5'-GGCTCGTCACCTTCGTGAATAC-3' } \\
\text { Reverse 5'-TCCATCTCTGGTCTCAACCG-3' }\end{array}$ & 234 \\
\hline Snail & $\begin{array}{l}\text { Forward 5'-CTTGTGTCTGCACGACCTGT-3' } \\
\text { Reverse 5'-CTTCACATCCGAGTGGGTTT-3' }\end{array}$ & 167 \\
\hline
\end{tabular}

Down-regulation of MMP-9 expression was verified by RT-PCR and Western blot analysis.

\section{Western Blot Analysis}

Lysates from an equal number of cells were obtained by Tris glycine SDS sample buffer (Gradipore, Frenchs Forest, Australia), homogenized, and loaded on 12-well NuPAGE 4 to 12\% Bis-Tris gel (Invitrogen) for electrophoresis under reduced conditions. After electrophoresis, the proteins were electron transferred onto nitrocellulose membrane for 3 hours using Mini Trans-Blot Electrophoretic Transfer Cell (Bio-Rad, Hercules, CA). For immunodetection, membranes were blocked in 5\% skim milk in PBS overnight at $4^{\circ} \mathrm{C}$ and incubated for 1 hour at room temperature with the following primary antibodies: mouse monoclonal anti-E-cadherin (1/2000; BD bioscience), mouse monoclonal anti-cytokeratin (1/2000; Sigma), rabbit polyclonal anti-vimentin (1/1000), rabbit polyclonal anti- $\alpha$ SMA $(1 \mu \mathrm{g} / \mathrm{ml})$, mouse monoclonal anti$\beta$-actin (1:2000; Sigma), rabbit polyclonal N-cadherin (5 $\mu \mathrm{g} / \mathrm{ml}$; Calbiochem), goat polyclonal anti-E-cadherin ( $\mathrm{N}$ terminal) (1:1000; Santa Cruz Biotechnology), and mouse monoclonal anti-MMP-9 (6-6B) $(1 \mu \mathrm{g} / \mathrm{ml}$; Calbiochem). The membranes were washed and incubated for 40 minutes with their respective horseradish peroxidase-conjugated secondary antibodies: donkey anti-goat- horseradish peroxidase (1:2000; Santa Cruz Biotechnology), goat anti-rabbit horseradish peroxidase (1:2000; Santa Cruz
Biotechnology), and goat anti-mouse horseradish peroxidase (1:2000; Abcam). Bands were visualized with an enhanced chemiluminescence detection kit.

\section{Zymography and Quantification}

MMP-2 and MMP-9 activity in AMCM, AMCM after MMP-9 removal by immunoprecipitation and medium derived from TGF- $\beta$ treated $\mathrm{C} 1.1$ cells was determined by gelatin zymography. Briefly, medium was mixed with Tris-Glycine SDS native sample buffer (1:1) (Invitrogen) and electrophoresed through 10\% Novex zymogram gelatin gels (Invitrogen) with Tris-Glycine SDS Running Buffer (Invitrogen) under constant voltage of $125 \mathrm{~V}$ for 90 minutes. After electrophoresis, the gel was incubated with zymogram renaturing buffer (Invitrogen) for 30 minutes at room temperature with gentle agitation and washed with developing buffer (Invitrogen) for 30 minutes. The gel was further incubated for 24 hours in fresh developing buffer at $37^{\circ} \mathrm{C}$. After developing, the gel was stained with $0.5 \%(\mathrm{w} / \mathrm{v})$ Coomassie Blue R-250 (Bio-Rad) in 50\% (v/v) methanol, $10 \%(\mathrm{v} / \mathrm{V})$ acetic acid for 30 minutes at room temperature. The gel was then destained with $50 \%(\mathrm{v} / \mathrm{v})$ methanol, $10 \%$ $(\mathrm{v} / \mathrm{v})$ acetic acid for 30 minutes at room temperature, and the gelatinolytic activity was visualized as a clear band on a blue background. Band intensity was quantified by densitometry using Adobe Photoshop 8 software. Briefly, zymogram gels were scanned using Kodak gel logic 100 imaging system and processed into gray scale images 
using Adobe Photoshop 8 software. Gray scale images were quantified densitometrically by the measurement of the mean intensity of positive band multiplied by its corresponding area. The optical band intensity was then corrected by subtracting background intensity of equal area.

\section{Immunoprecipitation}

Immunoprecipitation of conditioned medium was performed as per manufacturer's protocol (Roche Applied Science, Mannheim, Germany). Briefly, $1.5 \mathrm{ml}$ of conditioned medium was incubated with $5 \mu \mathrm{g}$ of mouse monoclonal anti-MMP-9 (6-6B) or goat polyclonal anti-E-cadherin (N-terminal) $\mathrm{Ab}$ for 3 hours at 2 to $8^{\circ} \mathrm{C}$ on a rocking platform. The immune complexes were absorbed by the addition of $50 \mu$ l of protein G-agarose and incubated for 3 hours at 2 to $8^{\circ} \mathrm{C}$ on a rocking platform. The $\mathrm{Ab}$-immune complexes were separated by centrifugation and medium was collected for cell culture. The Ab-immune complexes were washed and immunoprecipitates were collected in Tris glycine SDS sample buffer for Western blot analysis.

\section{Cell Viability Assay}

Cell viability was determined by measuring lactate dehydrogenase (LDH) enzyme activity released from damaged cells using LDH-Cytotoxicity assay kit (BioVision, Mountain View, CA), as per the manufacturer's instructions. Briefly, medium alone was used as background, medium collected from nontreated cells as the negative control, $1 \%$-triton $\mathrm{X}-100$ treated cells as positive control and percentage cytotoxicity was calculated as [(test sample-negative control)/(positive control-negative control)] $\times 100$. The absorbance of all samples was detected in duplicate at $490 \mathrm{~nm}$ using a microplate reader and all experiments were repeated at least three times. Viability in $\mathrm{C} 1.1$ cells treated with AMCM, rMMP-9, or TGF- $\beta$ was determined. There was a slight decrease in cell viability in C1.1 cells induced by AMCM (88.7 $\pm 8.0 \%$ versus $95.4 \pm$ $2.1 \%, P=\mathrm{NS})$ and higher by TGF- $\beta(85.2 \pm 3.2 \%$ versus $95.4 \pm 2.1 \%, P<0.05)$ as compared with control medium treated C1.1 cells (see Supplemental Figure S1 at http://ajp.amjpathol.org). Viability in C1.1 cells induced by rMMP-9 was comparable with that of control medium treated $\mathrm{C} 1.1$ cells $(94.6 \pm 1.9 \%$ versus $95.4 \pm$ $2.1 \%, P=$ NS) (see Supplemental Figure S1 at http://ajp.amjpathol.org).

\section{Animal and Unilateral Ureteral Obstruction}

BALB/c mice approximately 4 weeks old, weighing at 18 to $20 \mathrm{~g}$ were purchased from the Australian Research Council and maintained under clean conditions in the Department of Animal Care at Westmead Hospital. Experiments were performed in accordance with protocols approved by Animal Ethics Committee of Western Sydney Area Health Service. Left proximal ureteral ligation was performed under anesthesia as described else- where. ${ }^{21}$ A total of four mice each were used for control and experimental groups. Both obstructed kidney and the contralateral right unobstructed kidney specimens were harvested from mice at 2 weeks after unilateral ureteral obstruction (UUO).

\section{Statistical Analysis}

Results from at least three independent experiments were expressed as mean \pm standard deviations. Significant differences between two data groups were performed by Student's $t$-test and a $P$ value of less than 0.05 was considered statistically significant.

\section{Results}

\section{AMCM Induces Phenotypic Conversion of C1.1 Cells from Epithelial to Mesenchymal Phenotype}

Tubular epithelial C1.1 cells were cultured in AMCM derived from lipopolysaccharide-activated J774 macrophages. Subconfluent C1.1 cells cultured in AMCM showed morphological changes typical of EMT, namely transition from epithelial cobblestone to fibroblastic spindle-shaped morphology after 48 hours of treatment (Figure 1A). Quantitative cell count revealed that the number of spindle-shaped cell was significantly increased among C1.1 cells cultured in AMCM compared with control medium (from $3.4 \pm 1.9 \%$ to $51.7 \pm 12.5 \%, P<0.001$ ) (Figure 1B). The transition of epithelial to mesenchymal phenotype was confirmed by real-time PCR analysis where the expression of E-cadherin and cytokeratin mRNA were significantly down-regulated (by $43.3 \pm$ $5.2 \%, P<0.001 ; 32.4 \pm 2.7 \%, P<0.01)$ and the expression of $\alpha$-SMA, vimentin and snail transcriptional factor mRNA were significantly up-regulated in C1.1 cells cultured in AMCM compared with control medium (by $74.5 \pm 10.9 \%, P<0.01 ; 63.1 \pm 4.3 \%, P<0.001$; $108.4 \pm 11.0 \%, P<0.001$ ) (Figure $1 \mathrm{C}$ ). This was also demonstrated by immunofluorescence where C1.1 cells cultured in AMCM lost E-cadherin, membrane associated $\beta$-catenin and cytokeratin staining and acquired $\alpha$-SMA, vimentin, $\mathrm{N}$-cadherin, and fibronectin staining (Figure 1D). The specificity of immunofluorescence staining was confirmed by negative staining for each isotype control $\mathrm{Ab}$ (Figure 1D). Consistent with immunofluorescence, Western blot analysis revealed that the levels of E-cadherin and cytokeratin protein were decreased while those of $\alpha$-SMA, vimentin, and $\mathrm{N}$-cadherin protein were increased in C1.1 cells cultured in AMCM, as compared with control medium (Figure 1E). Taken together, these results demonstrate that $\mathrm{AMCM}$ is capable of inducing tubular cell EMT in C1.1 cells.

\section{MMP Inhibitor GM6001 Inhibits AMCM-Induced Tubular Cell EMT in C1.1 Cells}

To determine whether MMPs contribute to tubular cell EMT induced by AMCM in C1.1 cells, a broad spectrum 
A

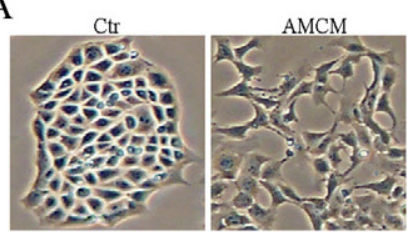

B

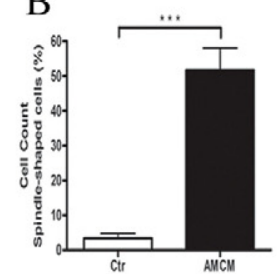

$\mathrm{C}$
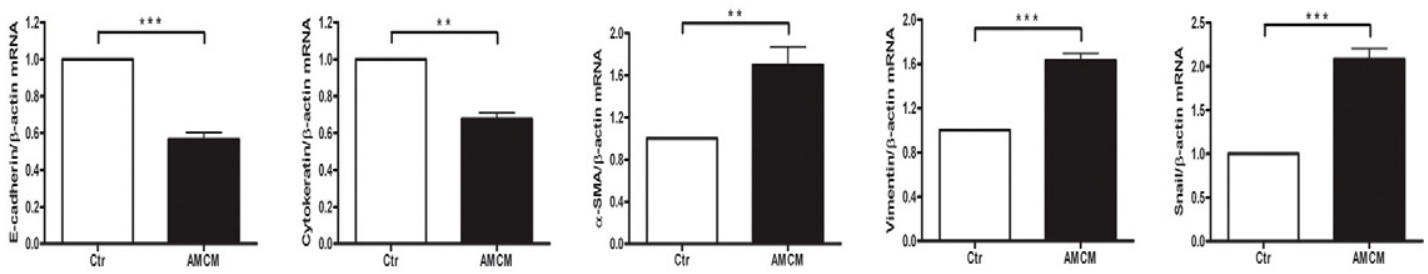

$\mathrm{D}$
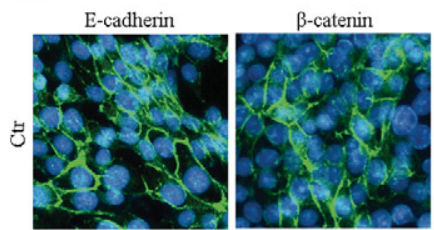

Cytokeratin
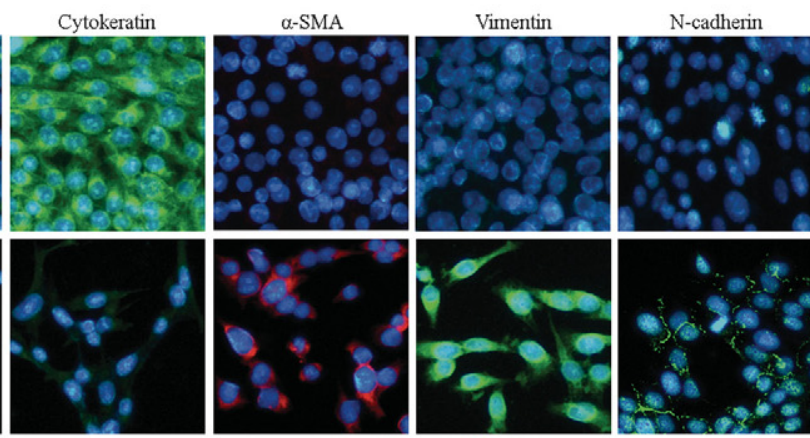

Fibronectin
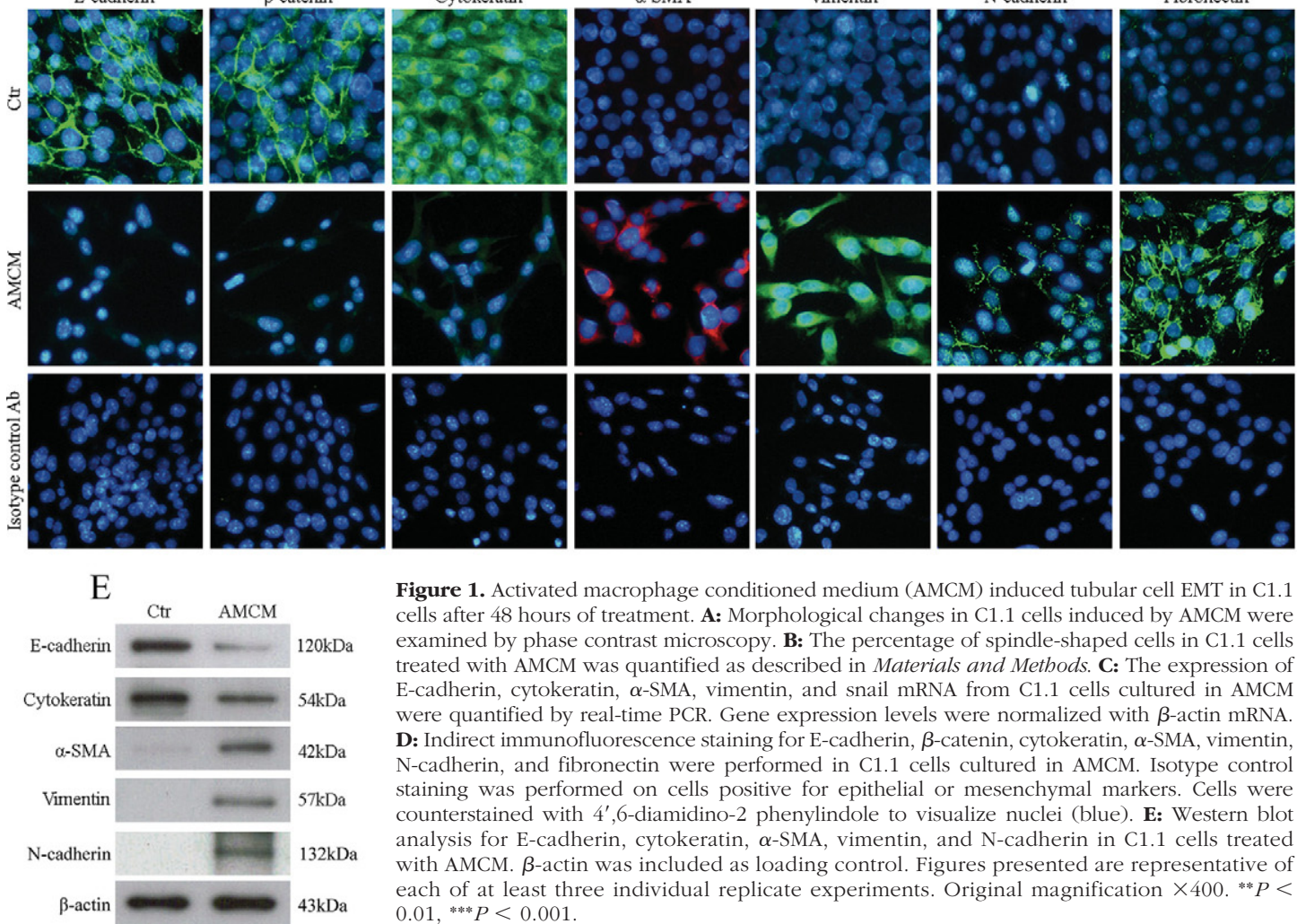

Figure 1. Activated macrophage conditioned medium (AMCM) induced tubular cell EMT in C1.1 cells after 48 hours of treatment. A: Morphological changes in C1.1 cells induced by AMCM were examined by phase contrast microscopy. B: The percentage of spindle-shaped cells in C1.1 cells treated with AMCM was quantified as described in Materials and Methods. C: The expression of E-cadherin, cytokeratin, $\alpha$-SMA, vimentin, and snail mRNA from C1.1 cells cultured in AMCM were quantified by real-time PCR. Gene expression levels were normalized with $\beta$-actin mRNA. D: Indirect immunofluorescence staining for E-cadherin, $\beta$-catenin, cytokeratin, $\alpha$-SMA, vimentin, $\mathrm{N}$-cadherin, and fibronectin were performed in C1.1 cells cultured in AMCM. Isotype control staining was performed on cells positive for epithelial or mesenchymal markers. Cells were counterstained with 4',6-diamidino-2 phenylindole to visualize nuclei (blue). E: Western blot analysis for E-cadherin, cytokeratin, $\alpha$-SMA, vimentin, and N-cadherin in C1.1 cells treated with AMCM. $\beta$-actin was included as loading control. Figures presented are representative of each of at least three individual replicate experiments. Original magnification $\times 400 .{ }^{* *} P<$ $0.01,{ }^{* * * *} P<0.001$.

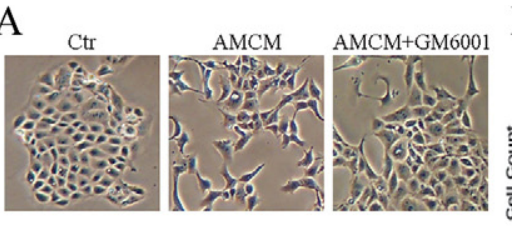

B

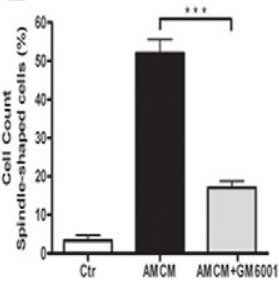

$\mathrm{C}$

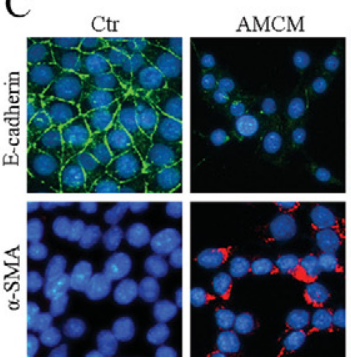

$\mathrm{D}$

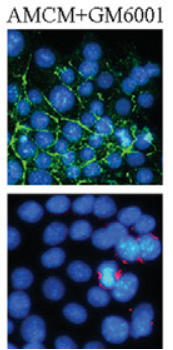

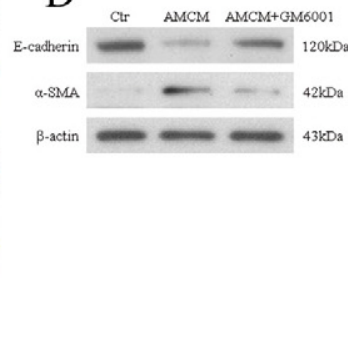

Figure 2. MMP-inhibitor (GM6001) inhibited AMCM-induced tubular cell EMT in C1.1 cells after 48 hours of treatment. A: Morphological changes in C1.1 cells induced by AMCM and in absence or presence of GM6001 were examined by phase contrast microscopy. B: The percentage of spindle-shaped cells observed in C1.1 cells treated with AMCM with or without GM6001 was quantified as described in Materials and Methods. C: Indirect immunofluorescence and (D) Western blot analysis for E-cadherin and $\alpha$-SMA were performed in C1.1 cells cultured in AMCM with or without GM6001. Original magnification $\times 400$. * * $P<0.001$. 
A

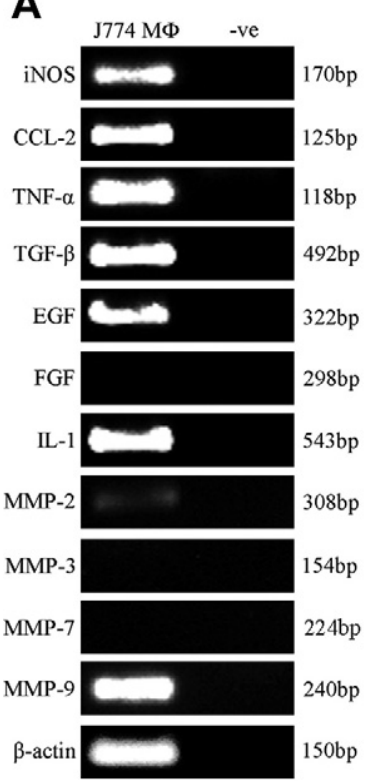

B
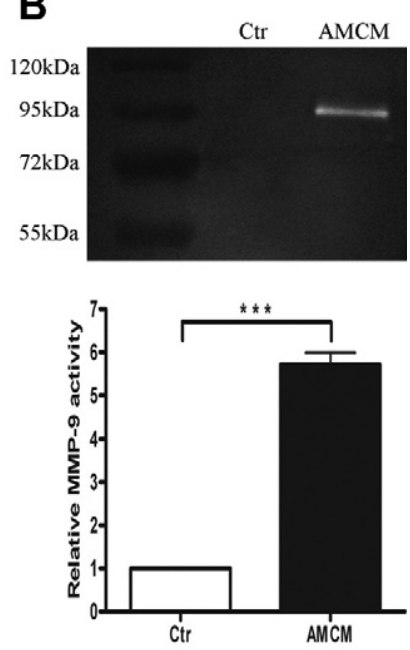

C

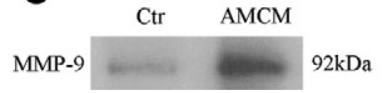

Figure 3. J774 macrophages expressed pro-fibrogenic growth factors and matrix metalloproteinases (MMP) after 24 hours of activation with lipopolysaccharide $(5 \mu \mathrm{g} / \mathrm{ml})$. A: Expression of inducible nitric oxide synthase, chemokine (C-C motif) ligand 2 , TNF- $\alpha$, TGF- $\beta$, epidermal growth factor, fibroblast growth factor, interleukin-1, MMP-2, MMP-3, MMP-7, and MMP-9 was analyzed by RT-PCR on RNA extracted from activated J774 macrophages. B: MMP-2 and MMP-9 activity in AMCM was determined by gelatin zymography and the relative activity of MMP-9 in AMCM was compared with control DMEM medium. C: Western blot analysis for MMP-9 using immunoprecipitate derived from medium of control and AMCM-treated C1.1 cells after 48 hours of treatment. ${ }^{* * * *} P<0.001$.

MMP inhibitor (GM6001) was used. After 48 hours of treatment, tubular cell EMT induced by AMCM in C1.1 cells was abrogated by GM6001 whereby the majority of C1.1 cells maintained typical epithelial cobblestone morphology and only a few cells exhibited fibroblastic spindle-shaped morphology (Figure 2A). This observation was confirmed by quantitative cell count analysis where the number of spindle-shaped cells induced by AMCM from $\mathrm{C} 1.1$ cells was significantly reduced by GM6001 (by $67 \%$, from $52.1 \pm 7.0 \%$ to $17.1 \pm 3.4 \%, P<0.001$ ) (Figure 2B), suggesting the role of MMP in AMCM-induced tubular cell EMT in C.1 cells. Consistent with this, immunofluorescence and Western blot analysis showed that the loss of E-cadherin and the induction of $\alpha$-SMA expression induced by the AMCM in C1.1 cells were abrogated by GM6001 (Figure 2, C and D). Collectively, these results indicate that MMP is involved in AMCMinduced tubular cell EMT in C1.1 cells.

\section{Activated $\mathbf{7 7 4}$ Macrophages Expressed Profibrogenic Growth Factors and MMPs}

To identify potential inducers of tubular cell EMT in C1.1 cells from AMCM, RT-PCR was performed on mRNA extracted from lipopolysaccharide-activated $\mathrm{J} 774$ macrophages. The activation status of $\mathrm{J} 774$ macrophages was confirmed by positive expression for inducible nitric oxide synthase, chemokine ( $\mathrm{C}-\mathrm{C}$ motif) ligand 2, and TNF- $\alpha$ (Figure 3A). We next analyzed the expression of

profibrogenic growth factors and MMPs that have previously been reported in EMT induction. Activated $\mathrm{J774}$ macrophages were positive for TGF- $\beta$, epidermal growth factor, and interleukin-1 mRNA and negative for fibroblast growth factor mRNA (Figure 3A). Despite the expression of profibrogenic growth factors by activated $\mathrm{J} 774$ macrophages, the fact that AMCM-induced tubular cell EMT in C1.1 cells was inhibited by GM6001 in this study suggests that AMCM-induced tubular cell EMT in C1.1 cells is largely MMP-dependent. In terms of MMP expression, activated $\mathrm{J} 774$ macrophages expressed MMP-2 and MMP-9, but not MMP-3 or MMP-7 (Figure 3A), suggesting the involvement of MMP-2 and MMP-9 in AMCMinduced tubular cell EMT in C1.1 cells. However, the likely involvement of MMP-2 was excluded because its expression was relatively weak compared with MMP-9 (Figure 3A) and gelatin zymography which is specific for the detection of MMP-2 and MMP-9 activity showed a clear proteolytic band only at $92 \mathrm{kDa}$, corresponding to the protein size of MMP-9 in AMCM (Figure 3B). Quantitative analysis showed a significant increase in MMP-9 activity in AMCM, as compared with control medium (5.72 \pm 0.46 -fold, $P<0.001$ ) (Figure 3B). The presence of MMP-9 protein in AMCM was detected by immunoprecipitation followed by Western blot (Figure 3C). Collectively, these results suggest that MMP-9 could be responsible for AMCM induced tubular cell EMT in C1.1 cells.

\section{rMMP-9 Induces Tubular Cell EMT in C1.1 Cells}

To determine whether MMP-9 contributes to AMCM-induced tubular cell EMT in C1.1 cells, we first examined whether rMMP-9 $(2 \mu \mathrm{g} / \mathrm{ml})$ was capable of inducing tubular cell EMT in $\mathrm{C} 1.1$ cells. After 48 hours of treatment, C1.1 cells showed a clear cut morphological transition from typical epithelial cobblestone appearance to fibroblastic spindle-shaped morphology (Figure 4A). The number of spindle-shaped cells was significantly increased in C1.1 cells treated with rMMP-9 (from $3.6 \pm$ $1.8 \%$ to $49.2 \pm 10.1 \%, P<0.01$ ) (Figure $4 \mathrm{~B}$ ). The transition of epithelial to mesenchymal phenotype induced by rMMP-9 in C1.1 cells was confirmed by quantitative real time-PCR analysis where the expression of E-cadherin and cytokeratin were significantly down-regulated (by $33.5 \pm 6.6 \%, P<0.05 ; 32.5 \pm 1.8 \%, P<0.001$ ) while the expression of $\alpha$-SMA, vimentin and snail transcriptional factor were significantly up-regulated (by $73.1 \pm 4.8 \%$, $P<0.001 ; 58.1 \pm 2.4 \% P<0.001 ; 62.6 \pm 5.9 \%, P<$ 0.001) (Figure 4C). Immunofluorescence staining also revealed that $\mathrm{C} 1.1$ cells treated with $\mathrm{rMMP}-9$ lost E-cadherin, membrane associated $\beta$-catenin and cytokeratin, and acquired $\alpha$-SMA, vimentin, $\mathrm{N}$-cadherin, and fibronectin expression (Figure 4D). Consistent with this, Western blot analysis showed that the expression levels of E-cadherin and cytokeratin proteins were decreased while the expression levels of $\alpha$-SMA, vimentin, and $\mathrm{N}$ cadherin proteins were increased in $\mathrm{C} 1.1$ cells treated with rMMP-9 (Figure 4E). Taken together, these results indicate that MMP-9 is capable of inducing tubular cell EMT in C1.1 cells. 
A

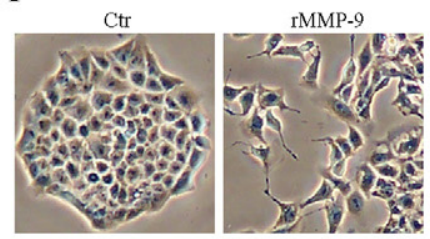

$\mathrm{D}$
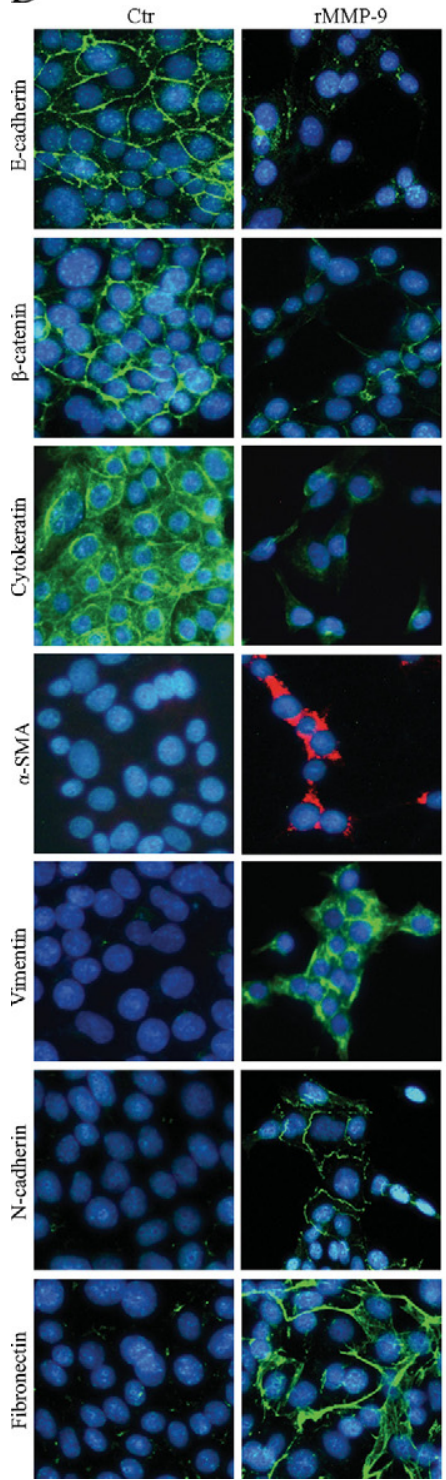

B

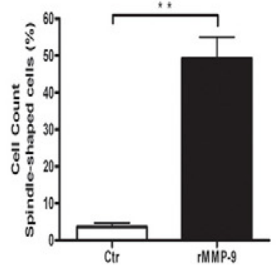

E

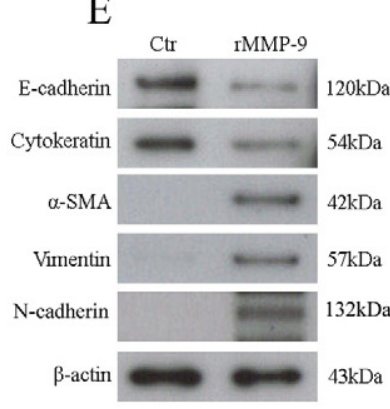

$\mathrm{C}$
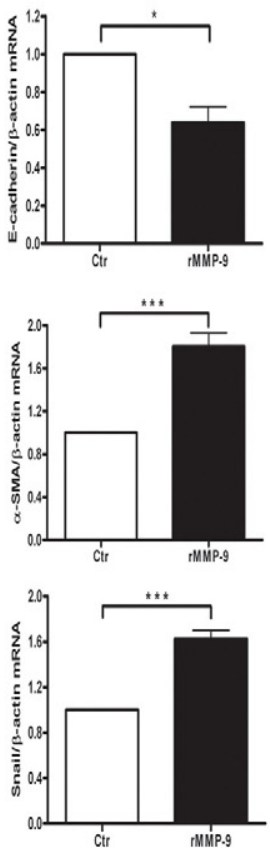
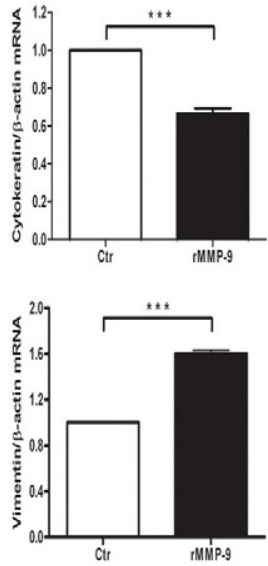
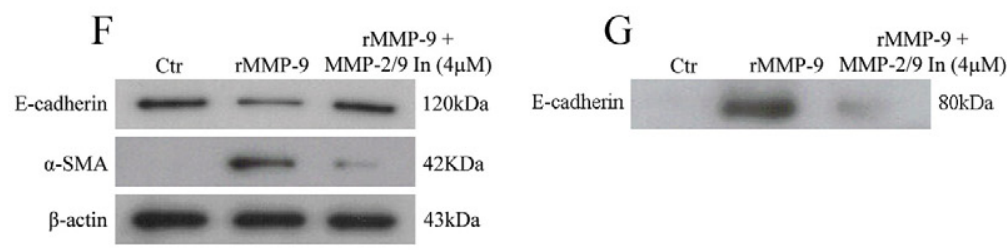

Figure 4. Treatment with recombinant MMP-9 (rMMP-9) for 48 hours induced tubular cell EMT in $\mathrm{C} 1.1$ cells. A: Morphological changes in C1.1 cells induced by rMMP-9 were examined by phase contrast microscopy. B: The percentage of spindle-shaped cells in C1.1 cells treated with rMMP-9 was quantified as described in Materials and Methods. C: The expression of E-cadherin, cytokeratin, $\alpha$-SMA, vimentin, and snail mRNA from C1.1 cells treated with rMMP-9 were quantified by real-time PCR. D: Indirect immunofluorescence staining for E-cadherin, $\beta$-catenin, cytokeratin, $\alpha$-SMA, vimentin, N-cadherin, and fibronectin was performed in C1.1 cells treated with rMMP-9. E: Western blot analysis for E-cadherin, cytokeratin, $\alpha$-SMA, vimentin, and $\mathrm{N}$-cadherin in C1.1 cells treated with rMMP-9. F: Western blot analysis for E-cadherin and $\alpha$-SMA expression in C1.1 cells treated with rMMP-9 with or without MMP-2/9 inhibitor. G: Western blot analysis for E-cadherin ectodomain using immunoprecipitate derived from medium of C1.1 cells treated with rMMP-9 or rMMP-9 with MMP-2/9 inhibitor. Original magnification $\times 400 .{ }^{*} P<$ $0.05,{ }^{* * *} P<0.01,{ }^{*}{ }^{\text {*** }} P<0.001$.

Our previous studies, ${ }^{19}$ along with others ${ }^{22}$ have reported that MMPs are capable of inducing EMT via the disruption E-cadherin/ $\beta$-catenin cell-to-cell adhesion complex. To verify that the induction of tubular cell EMT in C1.1 cells by rMMP-9 was due to its proteolytic activity and through the disruption of $\mathrm{E}$-cadherin $/ \beta$ catenin complex, MMP-2/9 inhibitor $(4 \mu \mathrm{mol} / \mathrm{L})$ was used and the byproduct of E-cadherin shedding, Ecadherin ectodomain $(80 \mathrm{kDa})$ was analyzed in medium derived from rMMP-9 and rMMP-9 with MMP-2/9 inhibitor treated C1.1 cells. Western blot analysis showed that the lost of E-cadherin and the acquisition of $\alpha$-SMA induced by rMMP-9 in C1.1 cells was prevented by MMP-2/9 inhibitor (Figure 4F). In addition, E-cadherin ectodomain was only detected in medium derived from rMMP-9, but not rMMP-9 with MMP-2/9 inhibitor treated C1.1 cells (Figure 4G). The result obtained is paralleled with the lost of E-cadherin and membrane associated $\beta$-catenin observed by immunofluorescence staining (Figure 4D), thus implicating dis- 
ruption of $\mathrm{E}$-cadherin/ $\beta$-catenin complex in the induction of tubular cell EMT in C1.1 cells by rMMP-9.

\section{MMP-2/9 Inhibitor Inhibits AMCM-Induced Tubular Cell EMT in C1.1 Cells}

To confirm the role of MMP-9 in tubular cell EMT induced by AMCM in C1.1 cells, a dual specific MMP-2/9 inhibitor was used. This particular inhibitor was selected for the assay because activated $\mathrm{J} 774$ macrophages expressed low levels of MMP-2 mRNA and no MMP-2 activity in AMCM was detected by gelatin zymography (Figure 3, A and $B$ ). Tubular cell EMT induced by AMCM in C1.1 cells was abrogated by MMP-2/9 inhibitor after 48 hours of treatment in a dose-dependent manner. The number of spindle-shaped cells observed in C1.1 cells cultured in AMCM was reduced by MMP-2/9 inhibitor at a dosage of $1 \mu \mathrm{mol} / \mathrm{L}$ (by $12 \%$, from $59.9 \pm 13.6 \%$ to $52.8 \pm 8.8 \%$, $P>0.05$ ), $2 \mu \mathrm{mol} / \mathrm{L}$ (by $48 \%$, to $31.0 \pm 3.4 \%, P<0.05$ ), $3 \mu \mathrm{mol} / \mathrm{L}$ (by $73 \%$, to $16.3 \pm 2.0 \%, P<0.01$ ), and 4 $\mu \mathrm{mol} / \mathrm{L}$ (by $81 \%$, to $11.6 \pm 1.5 \%, P<0.01$ ) (Figure 5 , A and $\mathrm{B}$ ). Consistent with this, immunofluorescence and Western blot analysis showed that the loss of E-cadherin and the acquisition of $\alpha$-SMA induced by AMCM in C1.1 cells were prevented by the MMP-2/9 inhibitor in dosedependent manner (Figure 5, C and D). These results demonstrate that MMP-9 is responsible for AMCM induced tubular cell EMT in C1.1 cells.

\section{Removal of MMP-9 in AMCM Reduces AMCM-Induced Tubular Cell EMT in C1.1 Cells}

To further confirm the specific role of MMP-9 in AMCMinduced tubular cell EMT in C1.1 cells, we assessed whether the removal of MMP-9 from AMCM via immunoprecipitation would inhibit the induction of tubular cell EMT in C1.1 cells. Because TGF- $\beta$ is a well-recognized inducer of tubular EMT, the contribution of TGF- $\beta$ in AMCM-induced tubular cell EMT in C1.1 cells was established in this study by TGF- $\beta$ neutralizing Ab. We found that morphological changes induced by AMCM in $\mathrm{C} 1.1$ cells were prevented in AMCM after the removal of MMP-9 and in the presence of TGF- $\beta$ neutralizing $A b$ after 48 hours of treatment (Figure 6A). The number of spindle-shaped cells was significantly reduced in $\mathrm{C} 1.1$ cells cultured in AMCM after MMP-9 removal (by 50\%, from $54.7 \pm 5.9 \%$ to $27.1 \pm 0.7 \%, P<0.01$ ) and to a lesser extent by TGF- $\beta$ neutralizing Ab under maximal dosage of $30 \mu \mathrm{g} / \mathrm{ml}$ (by $28 \%$, to $39.6 \pm 3.1 \%, P<0.05$ ) (Figure 6B), suggesting a more prominent role for MMP-9 in AMCM-induced tubular cell EMT in C1.1 cells than TGF- $\beta$. Consistent with this observation, immunofluorescence and Western blot analysis demonstrated that the loss of E-cadherin and the acquisition of $\alpha$-SMA expression induced by AMCM in C1.1 cells were prevented in AMCM after MMP-9 removal and to a lesser extent by TGF- $\beta$ neutralizing $A b$ (Figure $6, C$ and D). The extent of MMP-9 removal via MMP-9 immunoprecipitation in this experiment was determined by gelatin zymography. We found that there was a significant decrease in MMP-9 activity in AMCM after MMP-9 immunoprecipitation (by $66.3 \pm 23.9 \%, P<0.01$ ) (Figure 6E). However, the removal of MMP-9 in AMCM was incomplete, which explained the lesser extent of inhibition in tubular cell EMT induced in C1.1 cells, as compared with that of MMP-2/9 inhibitor (Figure 5B). Taken together, these experiments further demonstrate the role of MMP-9 in AMCM-induced tubular cell EMT in C1.1 cells.

\section{Macrophage MMP-9 Is Responsible for AMCM-Induced EMT in C1.1 Cells}

We have previously reported that TGF- $\beta$-induced tubular cell EMT in a rat tubular epithelial NRK52e cells was abrogated by GM6001, ${ }^{19}$ suggesting the role of MMP in TGF- $\beta$ induced tubular cell EMT. Studies by Strutz et al ${ }^{15}$ showed that TGF- $\beta$ is capable of inducing MMP-2 and MMP-9 expression in NRK52e cells. In the current study, we sought to determine whether TGF- $\beta$-induced tubular cell EMT is dependent on MMP-2 and MMP-9 activity. To assess whether MMP-2 and MMP-9 contributes to TGF$\beta$-induced tubular cell EMT in C1.1 cells, MMP-2/9 inhibitor was used. We found that TGF- $\beta$-induced tubular cell EMT in C1.1 cells was prevented by MMP-2/9 inhibitor after 48 hours of treatment in a dose-dependent manner. Morphological changes induced by TGF- $\beta$ in $\mathrm{C} 1.1$ cells were reduced by MMP-2/9 inhibitor; the number of spindle-shaped cells was reduced at a dosage of $2 \mu \mathrm{mol} / \mathrm{L}$ (by $38 \%$, from $48.8 \pm 15.5 \%$ to $30.2 \pm 7.2 \%, P>0.05$ ), $3 \mu \mathrm{mol} / \mathrm{L}$ (by $70 \%$, to $14.8 \pm 2.3 \%, P<0.05$ ), and 4 $\mu \mathrm{mol} / \mathrm{L}$ (by $77 \%$, to $11.0 \pm 3.2 \%, P<0.05$ ) (Figure $7, \mathrm{~A}$ and $B$ ). Consistent with this, immunofluorescence and Western blot analysis showed that the loss of E-cadherin and the induction of $\alpha$-SMA expression induced by TGF- $\beta$ in C 1.1 cells were reduced by MMP-2/9 inhibitor in a dose-dependent manner (Figure 7, C and D). To confirm that TGF- $\beta$-induced tubular cell EMT was due to the induction of MMP-2 and MMP-9 expression in C1.1 cells, RT-PCR was performed on RNA extracted from TGF- $\beta$ treated $\mathrm{C} 1.1$ cells. The expression of both MMP-2 and MMP-9 were detected, however only MMP-9 expression was up-regulated by TGF- $\beta$ in C1.1 cells and the expression of MMP-2 was relatively weak, compared with MMP-9 (Figure 7E). Consistent with this, gelatin zymography showed a clear proteolytic band only corresponding to the protein size of MMP-9 $(92 \mathrm{kDa})$ in medium derived from TGF- $\beta$-treated $\mathrm{C} 1.1$ cells (Figure 7F), suggesting that only MMP-9 was responsible for TGF- $\beta$-induced tubular cell EMT in C1.1 cells. Quantitative analysis showed a significant increase in MMP-9 activity in medium derived from TGF- $\beta$-treated C1.1 cells, as compared with medium derived from $\mathrm{C} 1.1$ cells without TGF- $\beta$ treatment (5.74 \pm 1.13 -fold, $P<0.01$ ) (Figure 7F). The presence of MMP-9 protein was also detected by Western blot in medium derived from TGF- $\beta$-treated C1.1 cells by MMP-9 immunoprecipitation (Figure 7G). Collectively, these experiments demonstrate that TGF- $\beta$-induced tubular cell EMT in C1.1 cells is dependent on MMP-9 activity. 

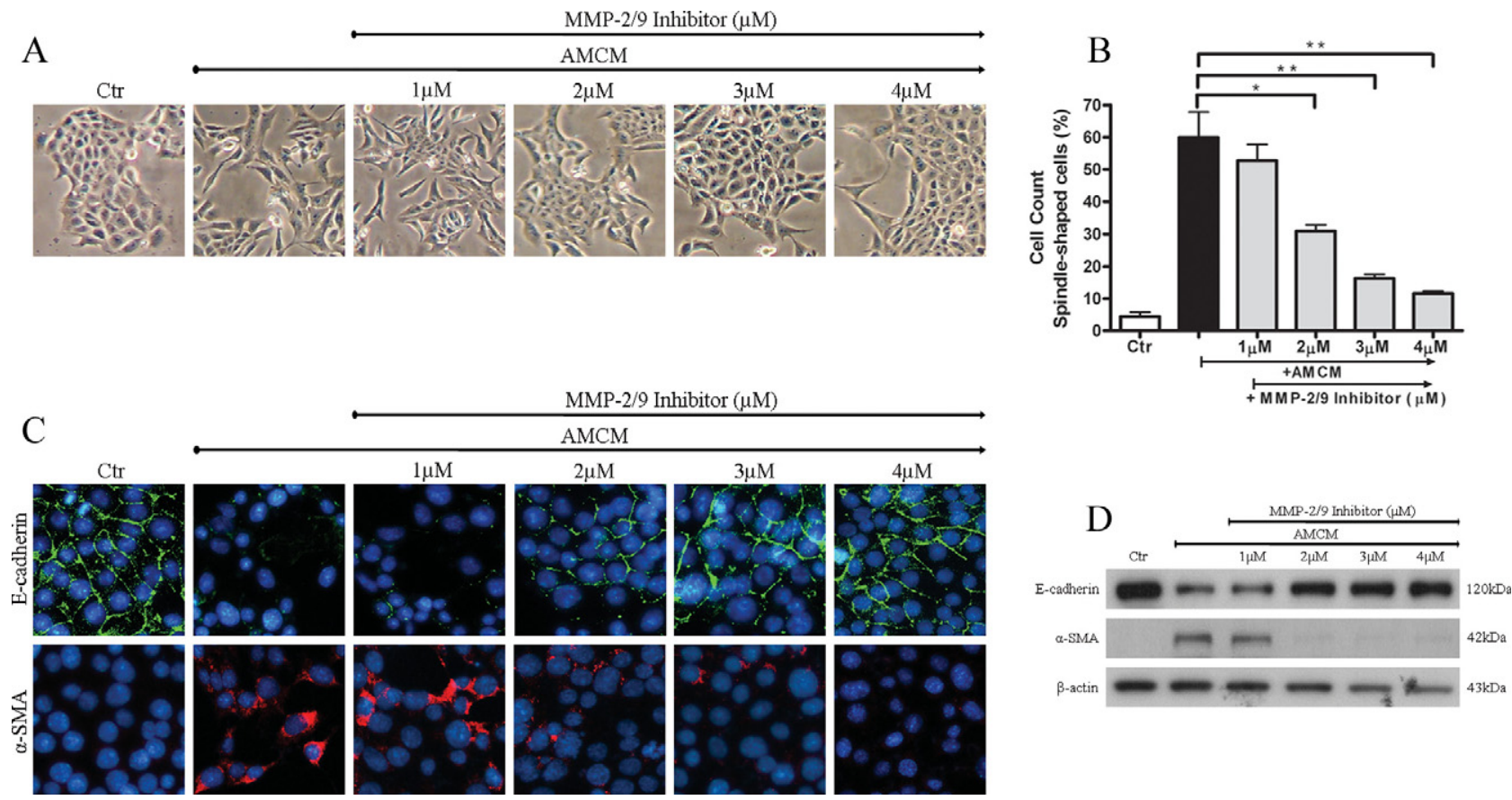

Figure 5. Treatment with MMP-2/9 inhibitor for 48 hours inhibited AMCM-induced tubular cell EMT in C1.1 cells in a dose-dependent manner (1, 2, 3, and 4 $\mu \mathrm{mol} / \mathrm{L}$ ). A: Morphological changes in C1.1 cells induced by AMCM in absence or presence of MMP-2/9 inhibitor were examined by phase contrast microscopy. B: The percentage of spindle-shaped cells observed in C1.1 cells treated with AMCM in absence or presence of MMP-2/9 inhibitor was quantified as described in Materials and Methods. C: Indirect immunofluorescence and (D) Western blot analysis for E-cadherin and $\alpha$-SMA in C1.1 cells treated by AMCM with or without MMP-2/9 inhibitor. Original magnification $\times 400 .{ }^{*} P<0.05,{ }^{* *} P<0.01$.

TGF- $\beta$ is expressed by activated J774 macrophages, and we herein demonstrated that TGF- $\beta$ can induce MMP-9 expression in $\mathrm{C} 1.1$ cells and that MMP-9 is responsible for TGF- $\beta$-induced tubular cell EMT in
C1.1 cells. Therefore it was necessary to clarify whether it is macrophage MMP-9 or endogenous MMP-9 induced by TGF- $\beta$ in C1.1 cells that is responsible for AMCM-induced tubular cell EMT. To address this question, we used siRNA
A

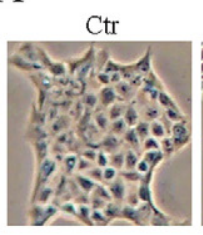

$\mathrm{C}$
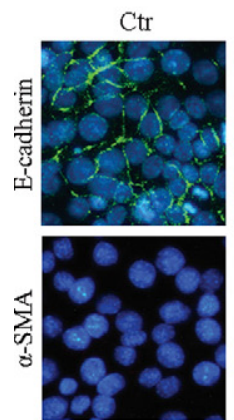

AMCM
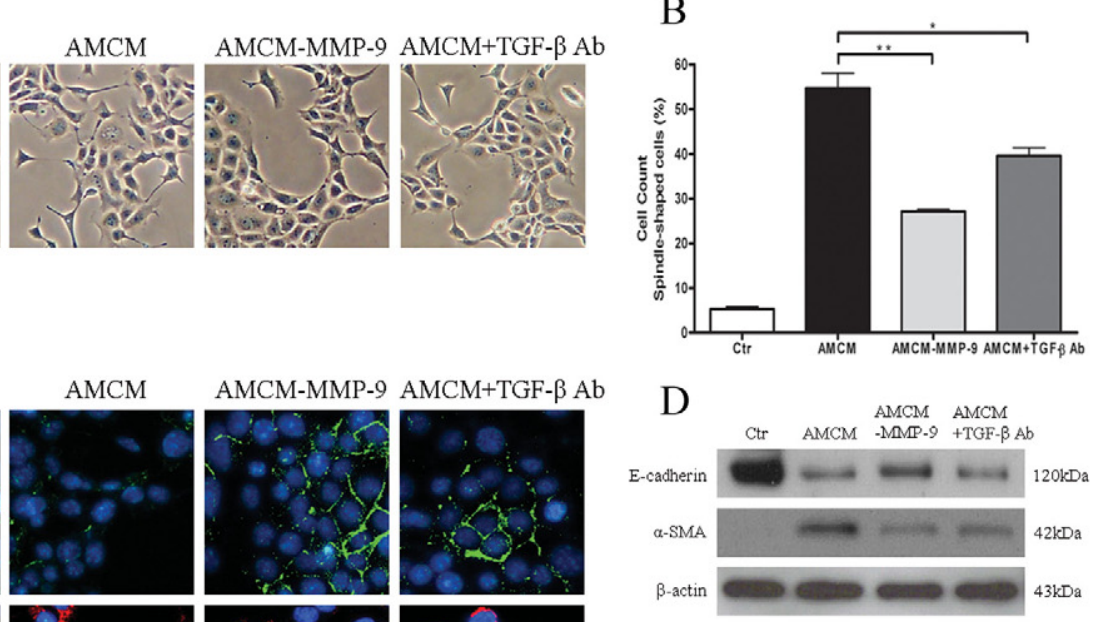

AMCM

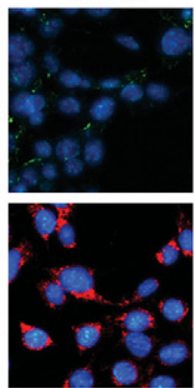

AMCM-MMP-9 AMCM+TGF- $\beta$ Ab
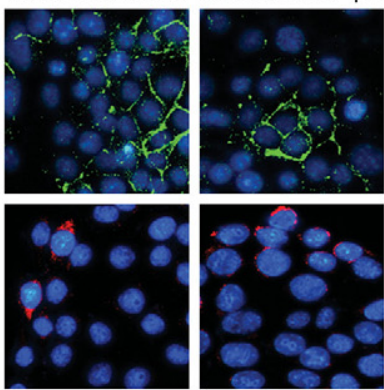

E
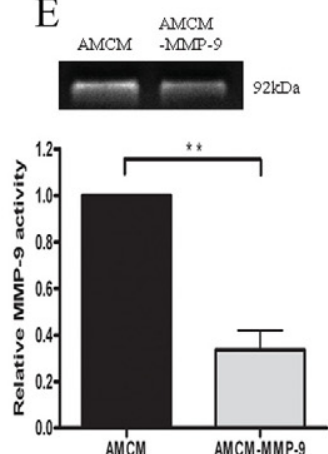

Figure 6. Inhibition of AMCM-induced tubular cell EMT in C1.1 cells after MMP-9 removal by immunoprecipitation and by TGF- $\beta$ neutralizing Ab. A: Morphological changes in C1.1 cells induced by AMCM, AMCM after MMP-9 removal or in presence of TGF- $\beta$ neutralizing Ab were examined by phase contrast microscopy. B: The percentage of spindle-shaped cells observed in C1.1 cells treated with AMCM, AMCM after MMP-9 removal, or in the presence of TGF- $\beta$ neutralizing Ab was quantified as described in Materials and Methods. C: Indirect immunofluorescence and (D) Western blot analysis for E-cadherin and $\alpha$-SMA in C1.1 cells treated with AMCM, AMCM after MMP-9 removal, or in the presence of TGF- $\beta$ neutralizing Ab. E: MMP-9 activity in AMCM was determined by gelatin zymography before and after MMP-9 removal by immunoprecipitation. The relative activity of MMP-9 in AMCM, before and after MMP-9 removal was compared. Original magnification $\times 400 .{ }^{*} P<0.05,{ }^{* *} P<0.01$. 

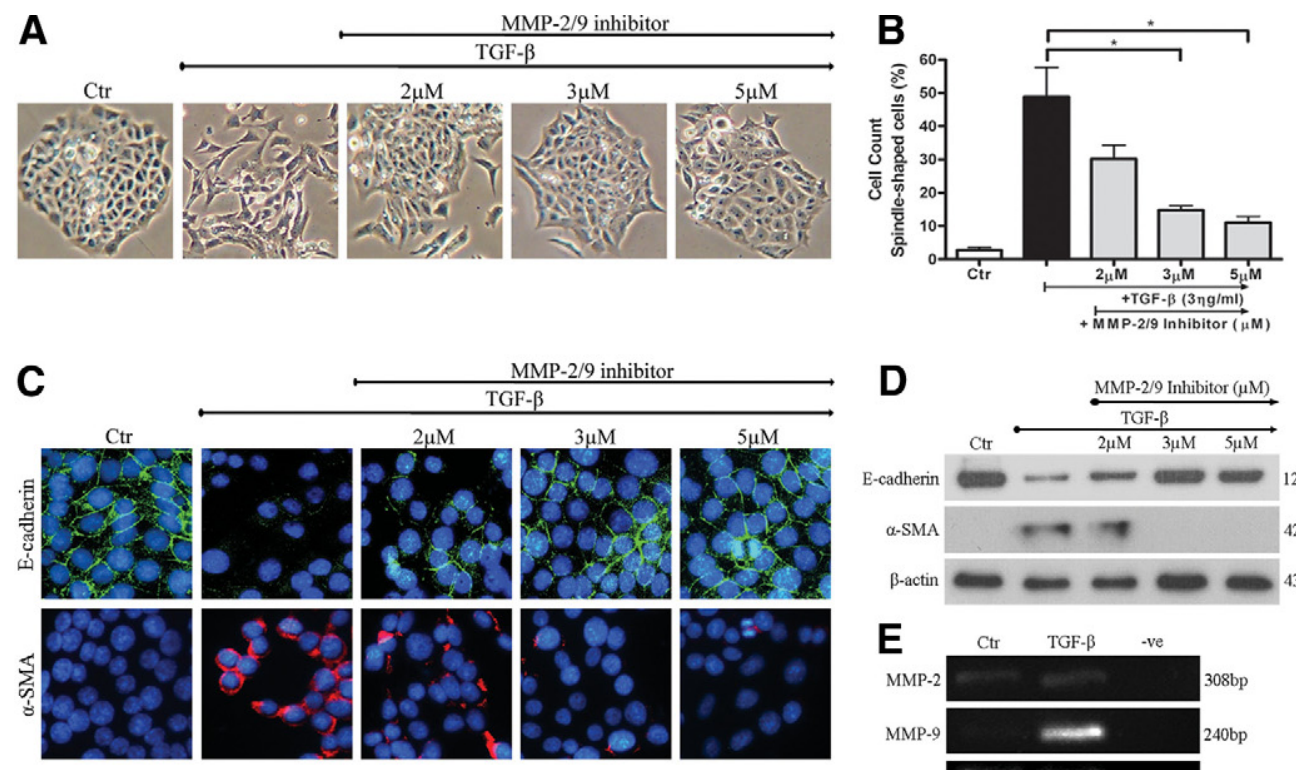

MMP-2/9 inhibitor

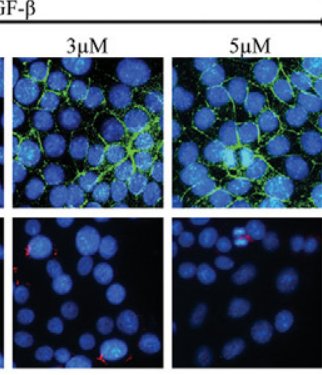

\section{$\mathbf{F}$}
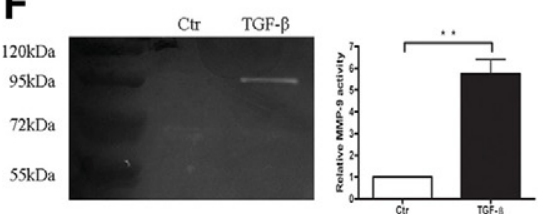

G

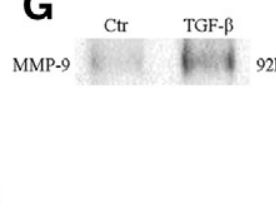

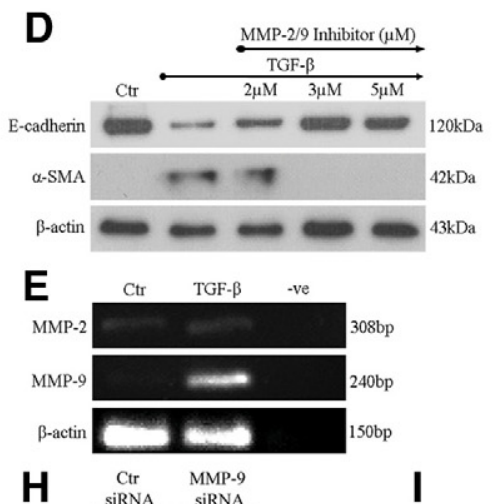

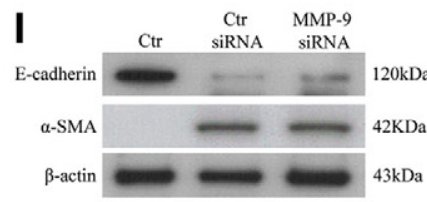

Figure 7. Macrophage secreted MMP-9 is responsible for the AMCM-induced EMT in C1.1 cells. A: Morphological changes in C1.1 cells induced by TGF- $\beta$ alone or in the presence of MMP-2/9 inhibitor $(2,3$, and $5 \mu \mathrm{mol} / \mathrm{L})$ were examined under phase contrast microscopy. B: The percentage of spindle-shaped cells observed in C1.1 cells treated with TGF- $\beta$ alone or in presence of MMP-2/9 inhibitor were quantified as described in Materials and Methods. C: Indirect immunofluorescence and (D) Western blot analysis for E-cadherin and $\alpha$-SMA in C1.1 cells treated with TGF- $\beta$ alone or in presence of MMP-2/9 inhibitor. E: Expression of MMP-2 and MMP-9 was analyzed by RT-PCR on RNA extracted from TGF- $\beta$ treated C1.1 cells. F: MMP- 2 and MMP-9 activity in medium derived from TGF- $\beta$ treated C1.1 cells was determined by gelatin zymography and the relative activity of MMP-9 in the medium was compared with medium derived from C1.1 cells treated with control medium. G: Western blot analysis for MMP-9 using immunoprecipitate derived from medium of control and TGF- $\beta$ treated C1.1 cells. H: Western blot and RT-PCR analysis for the expression of MMP-9 induced by TGF- $\beta$ in control and MMP-9 siRNA-transfected C1.1 cells. I: Western blot analysis for E-cadherin and $\alpha$-SMA expression in control and MMP-9 siRNA-transfected C1.1 cells treated with AMCM. Original magnification $\times 400 .{ }^{*} P<0.05,{ }^{* * *} P<0.01$.

directed against MMP-9 to reduce the expression of endogenous MMP-9 in C1.1 cells induced by TGF- $\beta$. MMP-9 induced by TGF- $\beta$ in $C 1.1$ cells was silenced by MMP-9 siRNA at both protein and mRNA levels, while control siRNA showed no silencing effect (Figure $7 \mathrm{H}$ ). In $\mathrm{C} 1.1$ cells transfected with control and MMP-9 siRNA, the extent of the loss of E-cadherin and the acquisition of $\alpha$-SMA protein expression level induced by AMCM was very similar (Figure $7 \mathrm{l}$ ). These results suggest that macrophage MMP-9 is responsible for AMCM-induced tubular cell EMT in C1.1 cells.

\section{Macrophage MMP-9 Induces Tubular Cell EMT in Primary TECS}

To investigate whether macrophage MMP-9 can induce tubular cell EMT in primary TECs as was shown in the C1.1 tubular epithelial cell line, primary TECs were treated with rMMP-9 and AMCM. After 72 hours of treatment, both $\mathrm{rMMP}-9$ and AMCM induced morphological changes of EMT in primary TECs (Figure 8A). Immunofluorescence staining showed that primary TECs treated with rMMP-9 or AMCM lost E-cadherin, $\beta$-catenin, and cytokeratin expression, and acquired $\alpha$-SMA, vimentin, N-cad- herin, and fibronectin expression (Figure 8A). Isotype control $\mathrm{Ab}$ staining was negative for each marker (Figure 8A). Western blot analysis revealed decreased expression of E-cadherin and cytokeratin protein and increased expression of $\alpha$-SMA, vimentin, and $\mathrm{N}$-cadherin protein in primary TECs treated with rMMP-9 or AMCM (Figure 8B). To confirm that MMP-9 is responsible for AMCM-induced tubular cell EMT in primary TECs, MMP-2/9 inhibitor was used at the optimal dosage of $4 \mu \mathrm{mol} / \mathrm{L}$ (as determined from our earlier experiment). Both immunofluorescence and Western blot results showed that the loss of E-cadherin and the acquisition of $\alpha$-SMA induced by AMCM were prevented by MMP2/9 inhibitor (Figure 8, C and D). Collectively, these results demonstrate that macrophage MMP-9 is responsible for AMCM-induced tubular cell EMT in primary TECs.

\section{Macrophage MMP-9 Colocalized with $\alpha$-SMA in UUO}

Mouse UUO is a well-established model of tubulointerstitial fibrosis with prominent interstitial macrophage infiltration. Severe interstitial fibrosis developed after 2 weeks of UUO in obstructed kidney (Figure 9A). To explore 
A

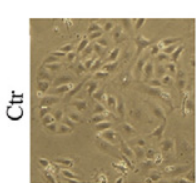

E-cadherin
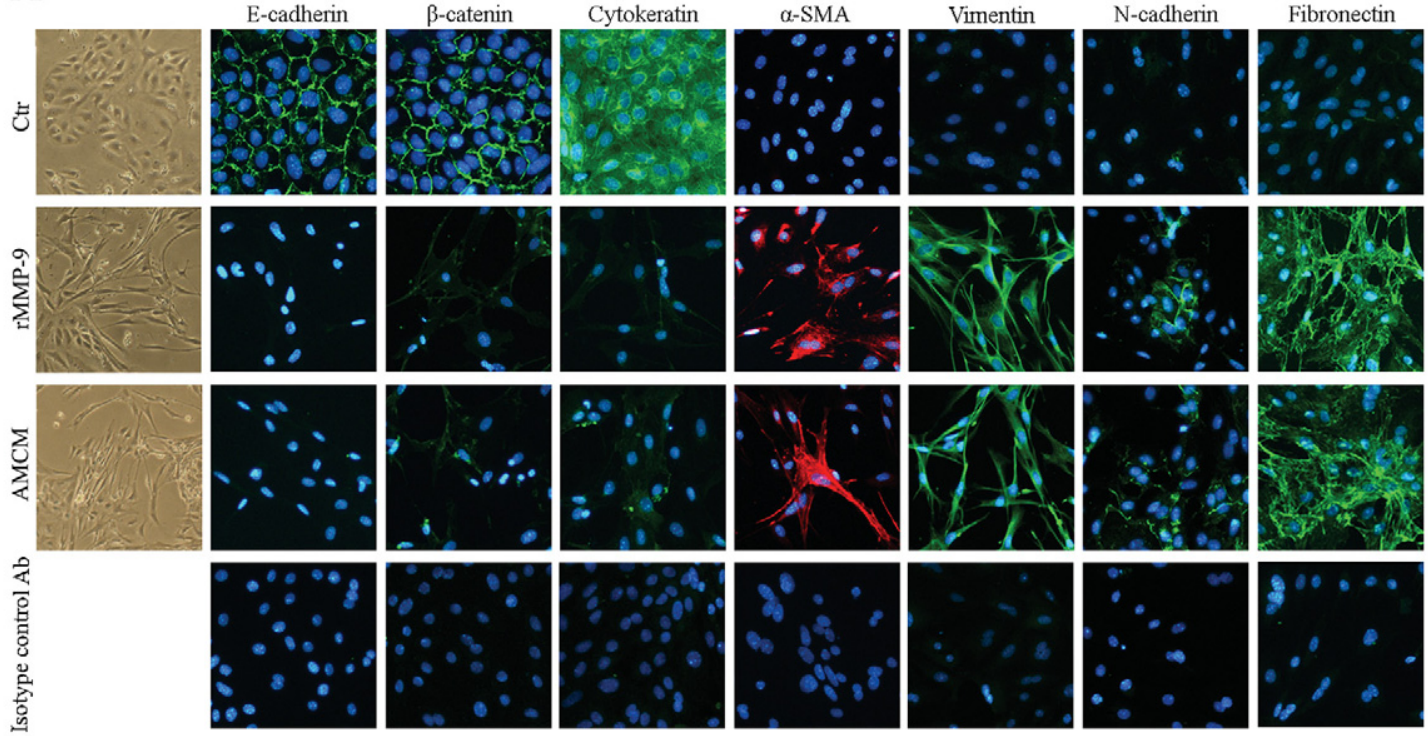

B

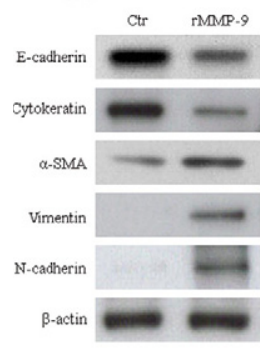

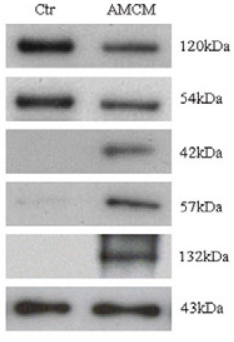

C

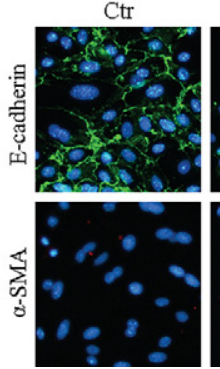

$\mathrm{AMCM}+$

AMCM MMP-2/9 In $(4 \mu \mathrm{M})$

D

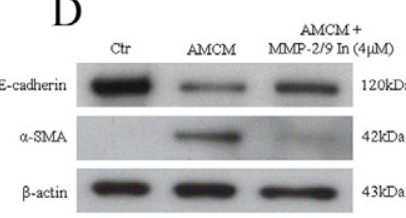

Figure 8. rMMP-9- and AMCM-induced tubular cell EMT in primary TECs after 72 hours of treatment. A: Morphological changes and the expression of E-cadherin, $\beta$-catenin, cytokeratin, $\alpha$-SMA, vimentin, N-cadherin, and fibronectin in primary TECs treated with rMMP- 9 or AMCM were examined by phase contrast microscopy and indirect immunofluorescence staining, respectively. Isotype control staining was performed on cells positive for epithelial or mesenchymal markers. B: Western blot analysis for E-cadherin, cytokeratin, $\alpha$-SMA, vimentin, and N-cadherin in primary TECs treated with rMMP-9 or AMCM. C and $\mathbf{D}$ : Indirect immunofluorescence and Western blot analysis for E-cadherin and $\alpha$-SMA expression in primary TECs cultured in AMCM with or without MMP-2/9 inhibitor. Original magnification $\times 400$.

the role of macrophage secreted MMP-9 in kidney fibrosis in vivo, we performed double immunofluorescence staining for MMP-9 within macrophages, and MMP-9 with $\alpha$-SMA in kidney sections of mice with UUO. Dual staining for macrophages and MMP-9 was found within the interstitium of kidneys (Figure 9B), indicating secretion of MMP-9 by infiltrating macrophages. $\alpha$-SMA staining was observed mainly in interstitium and in some tubular cells. Macrophage MMP-9 staining was found colocalized in areas of $\alpha$-SMA staining (Figure 9C), consistent with a role for macrophage MMP-9 in production of interstitial $\alpha$-SMA positive myofibroblasts through EMT.

\section{Discussion}

Macrophages are rich in profibrogenic growth factors and cytokines that are capable of inducing tubular cell
A

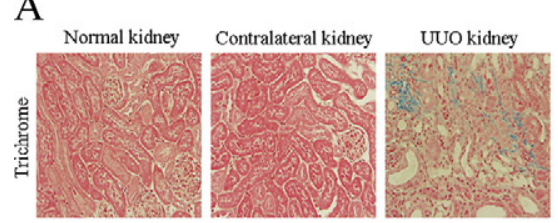

B
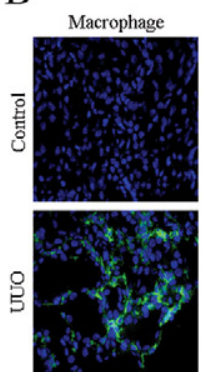

MMP-9
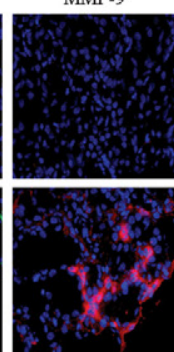

$\mathrm{C}$
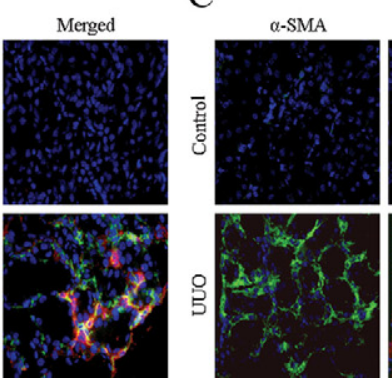

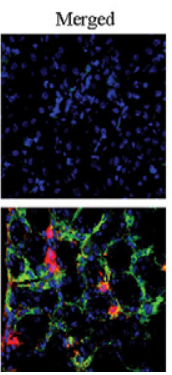

Figure 9. Macrophage colocalized with MMP-9 and $\alpha$-SMA staining in mouse kidney of unilateral ureteral obstruction. A: Gomori trichrome staining for interstitial fibrosis (blue). B: Single immunofluorescence staining for macrophages (green), MMP-9 (red) and dual staining (yellow) of macrophages with MMP-9. C: Single immunofluorescence staining for $\alpha$-SMA (green), MMP-9 (red), and colocalization of $\alpha$-SMA and MMP-9 staining. Original magnification $\times 400$. 
EMT, yet to our knowledge, the direct role of macrophages in tubular cell EMT induction has not been studied previously. Indeed, using an in vitro system, our present study has demonstrated that effector J774 macrophages cell line are capable of inducing tubular cell EMT in murine C1.1 tubular epithelial cell line and primary TECs, and that they do so through the activity of MMPsspecifically MMP-9. Furthermore, we have demonstrated, for the first time, that MMP-9 itself is capable of inducing tubular cell EMT and also contributes to TGF- $\beta$-induced tubular cell EMT.

Macrophages are well known to play a role in the development of renal fibrosis. In various experimental models, ablation of macrophages has been shown to markedly attenuate interstitial fibrosis. ${ }^{23,24}$ Macrophages may induce activation and proliferation of myofibroblasts, as well as contribute to the myofibroblast population in renal fibrosis via tubular cell EMT. Indeed, using a murine model of crescentic glomerulonephritis, Duffield et al ${ }^{24}$ showed that depletion of macrophages leads to a marked reduction in the number of interstitial myofibroblasts and also increased proliferation and apoptosis of interstitial myofibroblasts, in the presence of macrophages, suggesting a role for macrophages in maintaining the myofibroblast population in renal fibrosis. However, the role of macrophages in tubular cell EMT has not previously been assessed. Recently, Lange-Sperandio et $\mathrm{al}^{9}$ showed that blockade by chemokine receptor antagonist of leukocyte recruitment, including that of macrophages, reduced tubular cell EMT and renal fibrosis. Consistent with that observation, our in vitro study showed that conditioned medium derived from activated J774 macrophages can induce tubular cell EMT in C1.1 cells and primary TECs, providing direct evidence for a role for macrophages in tubular cell EMT induction. These findings are consistent with our observation that activated J774 macrophages expressed TGF- $\beta$, epidermal growth factor, and interleukin-1, each of which has previously been shown to have either a direct or indirect role in tubular cell EMT induction. ${ }^{15,25}$ However, through a series of inhibition experiments, we found that $\mathrm{J} 774$ macrophages induce tubular cell EMT in C1.1 cells and primary TECs via the secretion of MMPs, specifically MMP-9. This unexpected finding prompted us to examine the direct role of MMP-9 in tubular cell EMT induction.

In general, MMPs are better known for their role in preventing rather than causing fibrosis. However, MMPs are also known to play an important role in tubular cell EMT. MMP-2 and MMP-9, which specifically cleave type IV collagen and laminin, ${ }^{26,27}$ major constituents of tubular basement membrane, are thought to contribute to tubular cell EMT via disruption of basement membrane integrity, a crucial mechanism for allowing the transformed cell to migrate and invade the interstitial space. In fact, studies have shown that tubular cell EMT can be induced by MMP-2 and MMP-9 via the disruption of tubular basement membrane integrity. ${ }^{28,29}$ Moreover, the important contribution of MMP to tubular cell EMT has been demonstrated in IPA knockout mice, where the loss of MMP-9 expression resulted in the preservation of the structural integrity of basement membrane and inhibition of tubular cell EMT in obstructed renal injury. ${ }^{14}$ However, the exact contribution of MMP-2 and MMP-9 to tubular cell EMT may be more direct as Cheng et $\mathrm{al}^{18}$ have demonstrated that MMP-2 is necessary and sufficient to induce tubular cell EMT. Consistent with this observation, we have shown for the first time in the current study that MMP-9 itself is capable of inducing the entire course of tubular cell EMT in C1.1 cells and primary TECs. We observed all features of EMT, including loss of epithelial characteristics, acquisition of mesenchymal phenotype, and the production of extracellular matrix protein, fibronectin in C1.1 cells and primary TECs treated with MMP-9. In addition, the transformed cells acquired a migratory and invasive phenotype as evidenced by $\mathrm{N}$-cadherin expression, which has been shown to promote the migration and invasion of cancer cells. ${ }^{30,31}$ Jorda et $\mathrm{al}^{32}$ have shown that MMP-9 expression can be up-regulated by the transcription factor snail in the canine epithelial cell line (MDCK). This is consistent with our current demonstration that MMP-9 up-regulates the expression of snail in C1.1 cells, which may increase the expression of MMP-9 and further induce tubular cell EMT. Overall, these results suggest that the exact contribution of MMP-9 to renal fibrosis may have underestimated previously. This study and that of Cheng et al demonstrate a direct contribution of MMP-2 and MMP-9 to tubular cell EMT induction, independent of disruption of basement membrane integrity. However, the underlying mechanism of MMP-9-induced tubular cell EMT is unclear.

Although there are numerous distinct signaling pathway involved in the induction of EMT, ${ }^{33}$ proteolytic disruption E-cadherin/ $\beta$-catenin mediated cell-to-cell adhesion has been recognized as an important mechanism responsible for the induction of EMT. ${ }^{34,35}$ Studies by Mei et al have demonstrated that MMPs are capable of disrupting E-cadhein/ $\beta$-catenin complex, causing transnuclear localization of $\beta$-catenin and formation of a $\beta$-catenin/lymphoid enhancer factor- 1 transcriptional complex, ${ }^{22}$ which has been shown to induce EMT in tumors cells. ${ }^{36}$ In this study, we demonstrated that MMP-9 induced loss of the cell adhesion molecule, E-cadherin, along with its intracellular membrane associated $\beta$-catenin complex in C1.1 cells and primary TECs. Moreover, we demonstrated that MMP-9 induced tubular cell EMT in C1.1 cells and that the release of the ectodomain of E-cadherin in medium derived from MMP-9-treated C1.1 cells was dependent on its proteolytic activity, suggesting proteolytic shedding of E-cadherin by MMP-9. In another study using NRK52e cells we found that disruption of E-cadherin by MMPs mediated tubular cell EMT downstream of TGF$\beta 1 .{ }^{19}$ Consistent with our findings, recent studies have demonstrated that MMP-9 is capable of shedding Ecadherin ectodomain in ovarian carcinoma cells. ${ }^{37}$ Taken together, our results suggest that proteolytic disruption of E-cadherin/ $\beta$-catenin complex by MMP-9 initiates tubular cell EMT in $\mathrm{C} 1.1$ cells.

TGF- $\beta$ plays a key role in mediating renal fibrosis and its role in tubular cell EMT has been studied extensively. ${ }^{38}$ As a sole factor, TGF- $\beta$ is capable of inducing the entire course of tubular cell EMT and has also been recognized as its most potent inducer ${ }^{39}$ Moreover, other 
cytokines appear to play an indirect role dependent on TGF- $\beta$ induction, ${ }^{15}$ or function synergistically with TGF- $\beta$ to cause tubular cell EMT. ${ }^{25}$ We have shown that TGF- $\beta$ induced tubular cell EMT of NRK52e cells was abrogated by a broad-spectrum inhibitor of MMP activity, demonstrating the involvement of MMP in TGF- $\beta$-induced tubular cell EMT. ${ }^{19}$ It has been reported that TGF- $\beta$ is capable of inducing MMP-2 and MMP-9 expression by NRK52e cells. ${ }^{15}$ In the present study, using a different cell line, we observed induction of MMP-9 expression and activity of MMP-9 only in conditioned medium derived from C1.1 cells after TGF- $\beta$ treatment. We demonstrated that TGF$\beta$-induced tubular cell EMT in C1.1 cells was abrogated by the inhibition of MMP-9 activity, suggesting that MMP-9 may play a downstream role in TGF- $\beta$-induced tubular cell EMT in C1.1 cells. In support of a primary role for MMP-9 in induction of tubular cell EMT in C1.1 cells and primary TECs, MMP-9 secreted by interstitial macrophages was found colocalized with interstitial $\alpha$-SMApositive myofibroblasts in kidney of UUO mice. In preliminary studies, we have shown that inhibition of MMP-9 with MMP-2/9 inhibitor or MMP-9 neutralizing Ab significantly reduced renal fibrosis in UUO mice (unpublished). This result suggests a role of MMP-9 in renal fibrosis, however, whether the reduction in renal fibrosis was due directly to inhibition of tubular cell EMT is unclear, and more detailed investigation is required.

In summary, the results from our in vitro study demonstrate that MMP-9 secreted by macrophages may play a primary role in renal fibrosis via induction of tubular cell EMT. In addition, we highlighted the important role of MMP-9 in TGF- $\beta$-induced tubular cell EMT. Our results suggest that MMP-9 may be one of the key molecules responsible for renal fibrosis.

\section{References}

1. Nikolic-Paterson DJ, Lan HY, Atkins RC: Macrophages in immune injury. Edited by EG Neilson, WG Couser. Philadelphia, LippincottRaven, 1997, pp 575-592

2. Rodriguez-Iturbe B, Pons H, Herrera-Acosta J, Johnson RJ: Role of immunocompetent cells in nonimmune renal diseases. Kidney Int 2001, 59:1626-1640

3. Van Goor H, Ding G, Kees-Folts D, Grond J, Schreiner GF, Diamond JR: Macrophages and renal disease. Lab Invest 1994, 71:456-464

4. Hooke DH, Gee DC, Atkins RC: Leukocyte analysis using monoclonal antibodies in human glomerulonephritis. Kidney Int 1987, 31:964-972

5. Jones CL, Buch S, Post M, McCulloch L, Liu E, Eddy AA: Pathogenesis of interstitial fibrosis in chronic purine aminonucleoside nephrosis. Kidney Int 1991, 40:1020-1031

6. Jones CL, Buch S, Post M, McCulloch L, Liu E, Eddy AA: Renal extracellular matrix accumulation in acute puromycin aminonucleoside nephrosis in rats. Am J Pathol 1992, 141:1381-1396

7. Alpers CE, Hudkins KL, Floege J, Johnson RJ: Human renal cortical interstitial cells with some features of smooth muscle cells participate in tubulointerstitial and crescentic glomerular injury. J Am Soc Nephrol 1994, 5:201-209

8. Diamond JR: Macrophages and progressive renal disease in experimental hydronephrosis. Am J Kidney Dis 1995, 26:133-140

9. Lange-Sperandio B, Trautmann A, Eickelberg O, Jayachandran A, Oberle S, Schmidutz F, Rodenbeck B, Homme M, Horuk R, Schaefer F: Leukocytes induce epithelial to mesenchymal transition after unilateral ureteral obstruction in neonatal mice. Am J Pathol 2007, 171:861-871

10. Liu Y: Epithelial to mesenchymal transition in renal fibrogenesis: pathologic significance, molecular mechanism, and therapeutic intervention. J Am Soc Nephrol 2004, 15:1-12

11. Zeisberg EM, Potenta SE, Sugimoto H, Zeisberg M, Kalluri R: Fibroblasts in kidney fibrosis emerge via endothelial-to-mesenchymal transition. J Am Soc Nephrol 2008, 19:2282-2287

12. Lin SL, Kisseleva T, Brenner DA, Duffield JS: Pericytes and perivascular fibroblasts are the primary source of collagen-producing cells in obstructive fibrosis of the kidney. Am J Pathol 2008, 173:1617-1627

13. Iwano M, Plieth D, Danoff TM, Xue C, Okada H, Neilson EG: Evidence that fibroblasts derive from epithelium during tissue fibrosis. J Clin Invest 2002, 110:341-350

14. Yang J, Shultz RW, Mars WM, Wegner RE, Li Y, Dai C, Nejak K, Liu Y: Disruption of tissue-type plasminogen activator gene in mice reduces renal interstitial fibrosis in obstructive nephropathy. J Clin Invest 2002, 110:1525-1538

15. Strutz F, Zeisberg M, Ziyadeh FN, Yang CQ, Kalluri R, Muller GA, Neilson EG: Role of basic fibroblast growth factor-2 in epithelialmesenchymal transformation. Kidney Int 2002, 61:1714-1728

16. Ng YY, Huang TP, Yang WC, Chen ZP, Yang AH, Mu W, NikolicPaterson DJ, Atkins RC, Lan HY: Tubular epithelial-myofibroblast transdifferentiation in progressive tubulointerstitial fibrosis in 5/6 nephrectomized rats. Kidney Int 1998, 54:864-876

17. Orlichenko LS, Radisky DC: Matrix metalloproteinases stimulate epithelial-mesenchymal transition during tumor development. Clin Exp Metastasis 2008, 25:593-600

18. Cheng S, Lovett DH: Gelatinase A (MMP-2) is necessary and sufficient for renal tubular cell epithelial-mesenchymal transformation. Am J Pathol 2003, 162:1937-1949

19. Zheng G, Lyons JG, Tan TK, Wang Y, Hsu TT, Min D, Succar L, Rangan GK, Hu M, Henderson BR, Alexander SI, Harris DC: Disruption of Ecadherin by matrix metalloproteinase directly mediates epithelial-mesenchymal transition downstream of transforming growth factor-\{beta\}1 in renal tubular epithelial cells. Am J Pathol 2009, 175:580-591

20. Doctor RB, Chen J, Peters LL, Lux SE, Mandel LJ: Distribution of epithelial ankyrin (Ank3) spliceoforms in renal proximal and distal tubules. Am J Physiol 1998, 274:F129-F138

21. Moriyama T, Kawada N, Ando A, Yamauchi A, Horio M, Nagata K, Imai $\mathrm{E}$, Hori M: Up-regulation of HSP47 in the mouse kidneys with unilateral ureteral obstruction. Kidney Int 1998, 54:110-119

22. Mei JM, Borchert GL, Donald SP, Phang JM: Matrix metalloproteinase(s) mediate(s) NO-induced dissociation of beta-catenin from membrane bound E-cadherin and formation of nuclear beta-catenin/ LEF-1 complex. Carcinogenesis 2002, 23:2119-2122

23. Henderson NC, Mackinnon AC, Farnworth SL, Kipari T, Haslett C, Iredale JP, Liu FT, Hughes J, Sethi T: Galectin-3 expression and secretion links macrophages to the promotion of renal fibrosis. Am J Pathol 2008, 172:288-298

24. Duffield JS, Tipping PG, Kipari T, Cailhier JF, Clay S, Lang R, Bonventre JV, Hughes J: Conditional ablation of macrophages halts progression of crescentic glomerulonephritis. Am J Pathol 2005, 167:1207-1219

25. Fan JM, Huang XR, Ng YY, Nikolic-Paterson DJ, Mu W, Atkins RC, Lan HY: Interleukin-1 induces tubular epithelial-myofibroblast transdifferentiation through a transforming growth factor-beta1-dependent mechanism in vitro. Am J Kidney Dis 2001, 37:820-831

26. Birkedal-Hansen $\mathrm{H}$ : Proteolytic remodeling of extracellular matrix. Curr Opin Cell Biol 1995, 7:728-735

27. Lenz O, Elliot SJ, Stetler-Stevenson WG: Matrix metalloproteinases in renal development and disease. J Am Soc Nephrol 2000, 11:574-581

28. Zeisberg M, Bonner G, Maeshima Y, Colorado P, Muller GA, Strutz F Kalluri R: Renal fibrosis: collagen composition and assembly regulates epithelial-mesenchymal transdifferentiation. Am J Pathol 2001, 159:1313-1321

29. Zeisberg M, Maeshima Y, Mosterman B, Kalluri R: Renal fibrosis. Extracellular matrix microenvironment regulates migratory behavior of activated tubular epithelial cells. Am J Pathol 2002, 160:2001-2008

30. Hazan RB, Phillips GR, Qiao RF, Norton L, Aaronson SA: Exogenous expression of $\mathrm{N}$-cadherin in breast cancer cells induces cell migration, invasion, and metastasis. J Cell Biol 2000, 148:779-790

31. Qi J, Chen N, Wang J, Siu CH: Transendothelial migration of melanoma cells involves $\mathrm{N}$-cadherin-mediated adhesion and activation of the beta-catenin signaling pathway. Mol Biol Cell 2005, $16: 4386-4397$ 
32. Jorda M, Olmeda D, Vinyals A, Valero E, Cubillo E, Llorens A, Cano A, Fabra A: Upregulation of MMP-9 in MDCK epithelial cell line in response to expression of the Snail transcription factor. J Cell Sci 2005, 118:3371-3385

33. Kalluri R, Neilson EG: Epithelial-mesenchymal transition and its implications for fibrosis. J Clin Invest 2003, 112:1776-1784

34. Kleiner S, Faisal A, Nagamine Y: Induction of uPA gene expression by the blockage of E-cadherin via Src- and Shc-dependent Erk signaling. Febs J 2007, 274:227-240

35. Conacci-Sorrell M, Simcha I, Ben-Yedidia T, Blechman J, Savagner P, Ben-Ze'ev A: Autoregulation of E-cadherin expression by cadherincadherin interactions: the roles of beta-catenin signaling, Slug, and MAPK. J Cell Biol 2003, 163:847-857
36. Kim K, Lu Z, Hay ED: Direct evidence for a role of beta-catenin/LEF-1 signaling pathway in induction of EMT. Cell Biol Int 2002, 26:463-476

37. Symowicz J, Adley BP, Gleason KJ, Johnson JJ, Ghosh S, Fishman DA, Hudson LG, Stack MS: Engagement of collagen-binding integrins promotes matrix metalloproteinase-9-dependent E-cadherin ectodomain shedding in ovarian carcinoma cells. Cancer Res 2007, 67:2030-2039

38. Lan HY: Tubular epithelial-myofibroblast transdifferentiation mechanisms in proximal tubule cells. Curr Opin Nephrol Hypertens 2003, 12:25-29

39. Yang J, Liu Y: Dissection of key events in tubular epithelial to myofibroblast transition and its implications in renal interstitial fibrosis. Am J Pathol 2001, 159:1465-1475 